University of Louisville

ThinkIR: The University of Louisville's Institutional Repository

$12-2012$

\title{
Racial identity attitudes, perceived barriers, career self-efficacy, and career outcome expectations among African American male adolescents.
}

Norman L. Townsel 1960-

University of Louisville

Follow this and additional works at: https://ir.library.louisville.edu/etd

\section{Recommended Citation}

Townsel, Norman L. 1960-, "Racial identity attitudes, perceived barriers, career self-efficacy, and career outcome expectations among African American male adolescents." (2012). Electronic Theses and Dissertations. Paper 1452.

https://doi.org/10.18297/etd/1452

This Doctoral Dissertation is brought to you for free and open access by ThinkIR: The University of Louisville's Institutional Repository. It has been accepted for inclusion in Electronic Theses and Dissertations by an authorized administrator of ThinkIR: The University of Louisville's Institutional Repository. This title appears here courtesy of the author, who has retained all other copyrights. For more information, please contact thinkir@louisville.edu. 


\title{
RACIAL IDENTITY ATTITUDES, PERCEIVED BARRIERS,
}

\section{CAREER SELF-EFFICACY, AND CAREER OUTCOME EXPECTATIONS AMONG AFRICAN AMERICAN MALE ADOLESCENTS}

\author{
By \\ Norman L. Townsel, Jr., LPCC \\ M.Ed., Lindsey Wilson College, 2003 \\ A Dissertation \\ Submitted to the Faculty of the \\ College of Education and Human Development \\ of the University of Louisville \\ in Partial Fulfillment of the Requirements for the Degree of \\ Doctor of Philosophy \\ Counseling and Personnel Services, \\ Counselor Education - Mental Health Counseling
}

December 2012 


\title{
RACIAL IDENTITY ATTITUDES, PERCEIVED BARRIERS, CAREER SELF- EFFICACY AND CAREER OUTCOME EXPECTATIONS AMONG AFRICAN AMERICAN MALE ADOLESCENTS
}

\author{
By
}

Norman L. Townsel, Jr.

B.S., University of Maryland, 1987

M.Ed., Lindsey Wilson College, 2003

A Dissertation Approved on

November 28, 2012

By the following Dissertation Committee:

Nancy J. Cunningham, Ph.D., Dissertation Director

Vicki Hines Martin, Ph.D., RN, FAAN

Patrick Hardesty, Ph.D.

Michael J. Cuyjet, Ph.D.

Daya Sandhu, Ed.D., NCC, NCCC, NCSC, LPCC 


\section{ACKNOWLEDGEMENTS}

I would like to thank my Dissertation Committee Chair, Dr. Nancy Cunningham, and the Dissertation Methodologist, Dr. Patrick Hardesty for all of their hard work and patience. I would also like to thank the other committee members, Dr. Vicki Hines-Martin, Dr. Daya Sandhu, and Dr. Michael Cuyjet for their guidance and support. I would also like to thank my wife, Sheila, for her encouragement and support for me throughout this effort. She gave me strength and determination whenever I needed it. 


\begin{abstract}
RACIAL IDENTITY ATTITUDES, PERCEIVED BARRIERS, CAREER SELFEFFICACY, AND CAREER OUTCOM EXPECTATIONS AMONG AFRICAN AMERICAN MALE ADOLESCENTS
\end{abstract}

Norman L. Townsel Jr.

November 28, 2012

Social Cognitive Career Theory (SCCT) holds that self-efficacy and outcome expectations are primary predictors of career choice goals and actions, with contextual influences moderating those choices and actions. Racial identity research indicates that African American adolescents perceive more barriers than their White counterparts. The current study hypothesized that chronological age, racial identity attitudes, and the perception of barriers would be significant influences on self-efficacy and outcome expectations for African American adolescents.

The study explored the research question using two separate stepwise regression analyses. The first analysis explored racial identity attitudes, age, and perceived barriers in relation to self-efficacy. The second analysis utilized the same independent variables to assess their relationship to outcome expectations. Results of the first analysis found 
that $19 \%$ of the variance in career-related self efficacy was explained by the variables age, the perception of barriers, and the racial identity attitude Internalization Multiculturalist Inclusive as measured by the Cross Racial Identity Scale (Worrell, Vandiver, \& Cross, 2004). A significant model for the second analysis exploring the relationship of the independent variables to outcome expectations was not obtained. The racial identity attitude Immersion-Emersion Anti-White was the only variable related to career outcome expectations. Findings and implications for future research are discussed. 


\section{TABLE OF CONTENTS}

PAGE

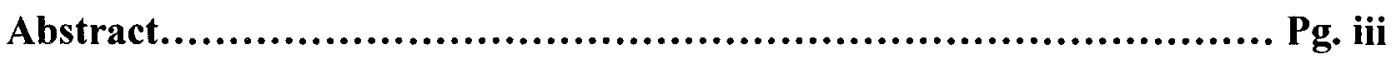

List of Tables and Figures............................................... Pg. ix

Chapter 1 Statement of the Problem.......................................Pg. 1

Study Overview..................................................... 7

Chapter 2 Literature review.............................................. 12

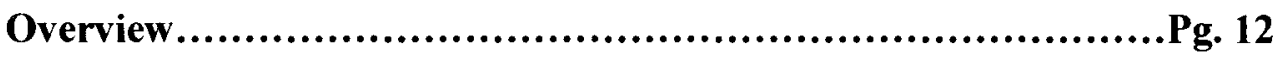

Choosing Between Racial Identity and Ethnic Identity as a Basis

for Research.......................................................... 12

Racial Identity Theory ................................................ 17

Racial Identity and Psychometric Assessment........................Pg. 36

Social Cognitive Career Theory.....................................Pg. 37

Contextual Barriers as a function of Race..........................Pg. 40

SCCT and Psychometric Assessment............................... 41

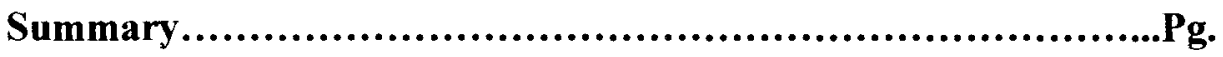

44Chapter 3 Method.......................................................... Pg. 45

Approval.................................................................. 45 


\section{TABLE OF CONTENTS (Continued)}

PAGE

Chapter $3 \quad$ Method (continued)............................................... 45

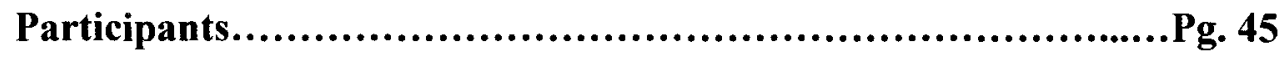

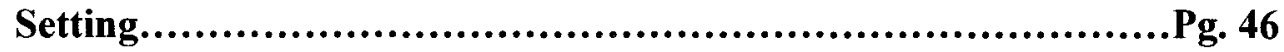

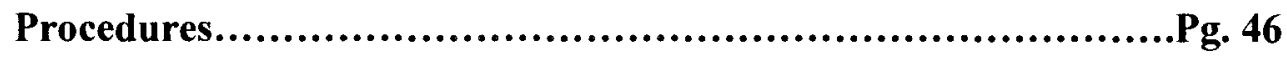

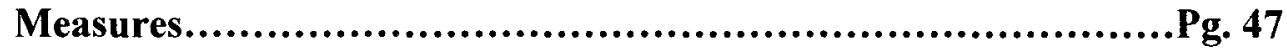

Hypotheses.......................................................... 51

Design............................................................... 52

Data Analysis......................................................... 53

Chapter $4 \quad$ Results....................................................... Pg. 55

Descriptive Analysis..................................................... 55

Multiple Regression Analyses......................................Pg. 60

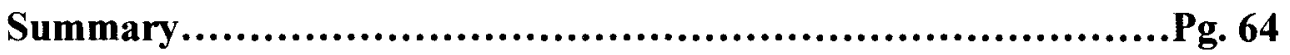

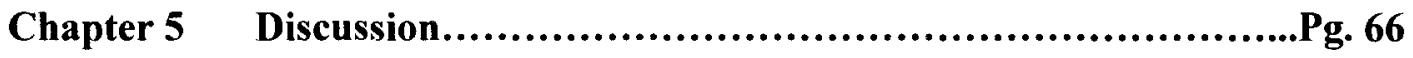

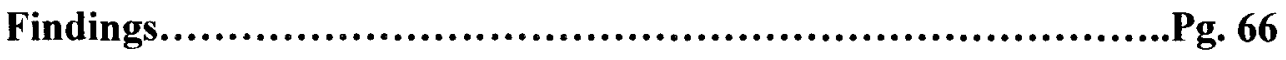

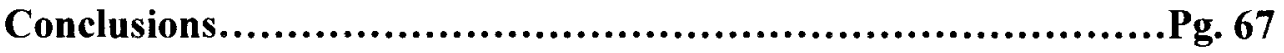

Study Limitations..............................................Pg. 72

Implications for Future Research..................................Pg. 74

Implications for Counseling Practice................................Pg. 75 


\section{TABLE OF CONTENTS (Continued)}

\section{PAGE}

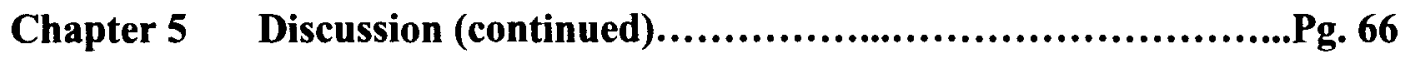

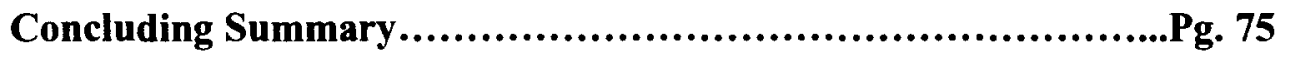

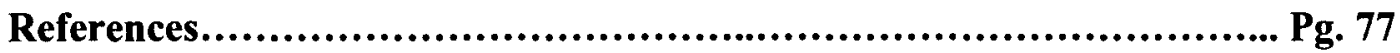

Curriculum Vitae........................................................Pg. 101 


\section{LIST OF TABLES AND FIGURES}

Table 1: Recent Research on Racial Identity Development in Adolescents.......Pg. 15

Table 2: Sample Questions from the CRIS Subscales..........................Pg. 32

Table 3: Internal Consistency Estimates (Cronbach Alpha).....................Pg. 51

Table 4: Range, Means and Standard Deviations of Independent and Dependent

Variables.........................................................................Pg. 56

Table 5: Frequency Distribution of Ages...................................... 57

Table 6: Correlations Between Independent Variables, Vocational Self Efficacy and

Vocational Outcome Expectations............................................Pg. 58

Table 7: Regression Coefficients.............................................Pg. 63

Figure 1: Mean Subscale Scores, Worrell 2008 Sample.....................Pg. 34, 68

Figure 2: Cluster Analysis of Racial Identity Profiles......................Pg. 35, 70 


\section{CHAPTER I}

\section{STATEMENT OF THE PROBLEM}

Many African American male adolescents in the United States develop and function in high risk environments. Poverty, exposure to violence, poor or absent parenting, unresponsive schools, and negative peers have all been cited as risk factors prevalent among African American children (Battin-Pearson, Newcomb, Abbott, Hill, Catalano, \& Hawkins, 2000). Research also indicates that poor academic self-concepts and perceived discriminatory experiences leave many of these children vulnerable to negative outcomes (Cokley, McClain, Jones, \& Johnson, 2011; Scott, 2003, 2004). Research shows that African American adolescents tend to perceive more barriers to social mobility than their White counterparts (Harris, 2006, 2008; Quimby, Wolfson, \& Seyala, 2007; Rollins \& Valdez, 2006; Constantine, Wallace, \& Kindachi, 2005; Smith, 2004), and that African American students who perceive more barriers to career success have lower vocational exploration and less commitment to career choice (Quimby et al., 2007).

A significant body of research suggests that, among African American adolescents, commitment to educational and career pursuits is also influenced by adolescent racial identity attitudes (Fordham \& Ogbu, 1986; Spencer, Dupree, \& Hartman, 1997; Noguera, 2001, 2008; Sellers, Copeland-Lindner, Martin, \& Lewis, 2006; Irving \& Hudley, 2005; Fryer, 2006). A common component of most racial 
identity theories describes strategies employed by African Americans to cope with negative reference group orientations, with many of the coping strategies employed assumed to result in unproductive or self-limiting behaviors. Racial identity development is usually described as context dependent (Noguera, 2008; Constantine, 2002; Spencer, Noll, Stoltzfus, \& Harpalani, 2001) and acknowledges that not all African Americans are at high risk. However, as described by Spencer et al. (2001), for many African American adolescent males, the experience of risk, coupled with the experience of stress, results in negative and reactive coping responses. As these negative responses become stable, they manifest as identity-related attitudes and behaviors, framed by the negative contexts within which they were formed. Cokley (2007) goes so far as to suggest that for African American clients, racial identity development may be the most important psychological construct for counseling practitioners to understand.

Theories on the importance of identity development in adolescence are not new. Erikson (1959) proposed that the chief task of adolescence is the successful achievement of identity. In describing his theory of the crisis between identity achievement and identity diffusion in adolescence, Erikson made the following observation:

In general it is primarily the inability to settle on an occupational identity which disturbs young people. To keep themselves together they temporarily overidentify, to the point of apparent complete loss of identity, with the heroes of cliques and crowds. On the other hand, they become remarkably clannish, intolerant, and cruel in their exclusion of others who are "different", in skin color or cultural background, in tastes and gifts, and often in entirely petty aspects of dress and gesture arbitrarily selected as the signs of an in-grouper or out-grouper. 
It is important to understand (which does not mean condone or participate in) such intolerance as the necessary defense against a sense of identity confusion (emphasis author's), which is unavoidable at a time of life when the body changes its proportions radically, when genital maturity floods body and imagination with all manner of drives, when intimacy with the other sex approaches and is, on occasion, forced on the youngster, and when life lies before one with a variety of conflicting possibilities and choices. Adolescents help one another temporarily through such discomfort by forming cliques and by stereotyping themselves, their ideals, and their enemies. (p. 97-98)

More recent identity theory has extended Erikson's concepts and includes perspectives on gender, sexual orientation, ethnicity, and other group characteristics. Recent racial identity research has focused on identifying specific attitudes associated with reference group orientation (Smith, Vandiver, Worrell, \& Cross, 2010), describing the internal attitudes associated with an individual's perception of the group differences that Erikson described. As Erikson's formulation of the "identity crisis" placed some importance on the career developmental aspects of adolescent identity achievement, recent racial identity research has explored the extent to which the developmental task of forming an occupational identity is influenced by racial identity attitudes (Constantine et al., 2005; Byars-Winston, 2006).

According to Cross (1991), racial identity attitudes perform three unique functions in the lives of African Americans: (1) defend against negative psychological stress; (2) provide a sense of purpose, meaning, and affiliation; and (3) facilitate social interaction with other racial and ethnic groups. A fundamental theme of racial identity 
development theory describes a period or state of conscious withdrawal from social interaction with other racial and ethnic groups, resulting in academic and economic disengagement by African American male adolescents. Depending on the particular theory, this disengagement is alternatively described as "negative coping" (Spencer et al., 1997), "cool pose" (Majors \& Billson, 1993), "self-segregation" (Noguera, 2008), "oppositional attitudes" (Ogbu, 2004), "cultural mistrust" (Hudley, 2005), or "anti-white attitudes" (Cross, 1971, 1991). In each instance, the disengagement results from the perception of a high degree of barriers to mobility and success. Many researchers have explored this phenomenon and placed an emphasis on the cultural behaviors of African American males, arguing that a subculture exists in the African American community that negatively influences the healthy development of educational and work values, leading to entrenched underperformance (Day-Vines \& Day-Hairston, 2005; Ogbu, 2004). Other researchers have focused attention on exploring structural barriers to employment for African American males, suggesting that the negative attitudes associated with educational and career disengagement are largely the result of an accurate assessment of the current opportunity structure (Weller \& Fields, 2011; Wilson, 2009; Decuir-Gunby, 2007).

Noguera (2008) rejects these singular approaches and suggests that focusing on structural and cultural factors as an "either/or" dynamic is inadequate, as neither concept alone can explain individual behavior. He argues that individuals act and make choices based upon the cognitive processes that provide them with the ability to adapt, cope, and respond; and that patterns of failure formed in adolescence, shaped by identity, have lasting consequences for hardships in adulthood. He argues that a number of risk factors 
in the environment have a multiplier effect on risk behavior - such as single-parent households, limited access to health care, poor nutrition, school-sorting practices, and exposure to substance abuse or violence. He also argues that the fact that so many African American males thrive when confronted with so many obstacles should encourage research in the areas of resilience, perseverance, and healthy coping strategies.

\section{Racial Identity and Career Development}

Current economic statistics suggest that the relationship between racial identity and African American career development remains an important area for study. Educationally, African Americans consistently underperform on federally-mandated achievement tests. Adolescent black males are not only more likely to have lower achievement but are also more likely to be disciplined and more likely to drop out. However, graduation rates for African American males do not fully explain disparate unemployment statistics, as unemployment rates for African Americans in the workforce are higher at every level of achieved education than the rates for Whites who have achieved the same level of education (U.S. Department of Labor, 2012). According to the United States Department of Labor (2012), African American males have consistently experienced unemployment at higher rates than any other major racial or ethnic group over the past forty years.

It is clear that the economic recession that began in 2008 significantly aggravated these historically poor outcomes. For example, in January 2007 the unemployment rate for Black workers was 7.9 percent, as compared to 4.2 percent for Whites. By June 2012, the unemployment rate had climbed to 14.4 percent for Blacks, as compared to 7.4 percent for Whites (U.S. Bureau of Labor Statistics, 2007, 2012). An analysis of the job 
market conducted in 2010 showed that younger workers, less educated workers, blue collar workers, service industry workers, and Black men were most adversely affected by the recession (Sum \& Khatiwada, 2010). A separate study of the nation's largest metropolitan areas showed that, in 25 communities, fewer than 55 percent of working-age Black males were currently employed (Levine, 2012). African Americans continue to be the only racial or ethnic group for whom women represent a larger share of the employed than do men. And among African American males between the ages of 16 to 19, the unemployment rate of $40 \%$ is consistently one of the highest for any population subgroup in the United States (U.S. Bureau of Labor Statistics, 2012).

Given these statistics, some have suggested that traditional career theory holds little salience for African Americans, as the research guiding these theories is almost exclusively taken from the experiences of White men (Brown, 2002; Walsh, Bingham, Brown, \& Ward, 2001). Examining the impact of work status among U.S. workers, Blustein (2006) suggests that racial identity theory may provide a valuable means for understanding the psychology of working for African Americans. Helms and Piper (1994) argue that predominant racial attitudes at the individual level will significantly influence the approach an individual takes to work-related tasks, yet challenges in extending this research remain. These include studying African American career development utilizing valid and reliable tools for the assessment of racial identity constructs (Cokley, 2007) and developing theoretical models that incorporate the work values of cultural minorities (Brown, 2002). 


\section{Study Overview}

Recent research grounded in Social Cognitive Career Theory (SCCT) continues to expand empirical findings related to gender and group differences in career interest and choice, primarily by acknowledging and incorporating the influence of contextual factors on personal agency and vocational development. Developed by Lent, Brown, and Hackett (1994), SCCT subscribes to Bandura's (1977) theory of reciprocal determinism (concurrent interaction among human cognitions, human behavior, and contextual variables). According to SCCT, vocational outcomes are determined by personal input variables (such as race, gender, intellectual ability, SES), an individual's learning experiences, and career interests that develop as a result of an individual's interaction with the environment. Specifically, six inter-related processes manifest at various stages of development during this timeframe: (1) acquisition of positive, yet realistic, selfefficacy and outcome expectations, (2) development of academic and career interests, (3) formation of linkages between interests and career-related goals, (4) translation of goals into action, (5) skill development and remediation of performance problems, and (6) negotiation of social supports and barriers that affect the pursuit of career options (Lent, Hackett, \& Brown, 1999). SCCT theorists view school-to-work transition as a process that gradually unfolds, beginning in the elementary school years and continuing through high school and beyond. They further propose that the acquisition of self-efficacy and outcome expectations, the development of career related interests, and the formation of provisional career goals are prominent tasks of elementary and middle school years, and that these goals are revisited and refined in high school (Lent et al., 1999). Explaining 
SCCT and the manner in which both internal and external factors serve to enhance or constrain personal agency, Albert and Luzzo (1999) state the following:

Some people are not granted the opportunity to make career choices under optimal conditions...for example, someone from an ethnic minority group may realize that there are few representatives in a certain career field from their ethnic group. Perceived barriers or impediments may arise in this individual due to their conceptual processes, differential opportunities for skill development, self-beliefs, standards and outcome expectations that may become internalized. Thus, this individual may prematurely foreclose on this potentially rewarding career because their environment has offered a limited amount of efficacy building opportunities or because a lack of ethnic minority representation in that career has led to an inaccurate set of self-efficacy beliefs or occupational outcome expectations. (p. 432)

Contextual barriers refer to obstacles one expects to encounter along the path to a given choice option and would precede the development of self-efficacy and outcome expectations for that option (Lent \& Brown, 2006). In the current study, the use of an SCCT framework to explore African American career development allows for the analysis of the perceived context surrounding the African American male adolescent's pursuit of a successful career, thus including the perception of career barriers as a relevant component of the study design. Contextual factors such as racial identity attitudes and perceived barriers have been included in previous studies and have shown significant relationships to social-cognitive variables (Constantine et al., 2005; ByarsWinston, 2006). 
Sellers, Copeland-Lindner, Martin, and Lewis (2006), point out that empirical evidence for a direct link between racial identity and psychosocial outcomes has been inconsistent. According to Cokley (2007), these inconsistencies may be partly attributable to assessment tools with marginal psychometric qualities. However, recent theory and research (Worrell, Vandiver, \& Cross, 2004) has led to the development of the Cross Racial Identity Scale (CRIS), which measures racial identity as a multidimensional set of six attitudes. Use of the CRIS in the current study is expected to yield more reliable results than previous studies that utilized less reliable measures (Cokley, 2007; Vandiver, Fhagen-Smith, Cokley, Cross, \& Worrell, 2001). The proposed study also offers a significant opportunity to add to the extant literature on racial identity, as few samples of adolescents have been used for previously published studies utilizing the CRIS.

In his revised theory of racial identity, Cross (1991) endeavors to explicate what learning experiences within a particular culture stimulate anxiety, fear, or other emotional responses and, thus, impact racial identity development. In research based on Cross's work, Ogbu (2003) found that the racial attitudes of African American adolescents shifted from grade 7 to grade 12, with the older group displaying a higher level of "oppositional" attitudes. Based on the theorizing of Cross (1991) and Lent et al. (1999) and the related research cited here, the current study hypothesized that learning experiences related to race that occur during adolescence will influence the perception of barriers to successful career development, career self-efficacy, and career outcome expectations in African American adolescent males. In addition, given the research related to changes that occur in racial identity development during adolescence, this study 
also hypothesized that age is related to both racial identity development and the perception of barriers to successful career development in African American adolescent males.

Several research investigations were used to guide the design of the study. Ali, McWhirter, and Chronister (2005) explored the relationship between perceived barriers, self-efficacy, and outcome expectations for adolescents of lower socioeconomic status. Results indicated that perceived barriers did not account for any variance associated with outcome expectations. However, less than one percent of the sample self-identified as African American. Byars-Winston (2006) explored the relationship of racial ideology to self-efficacy, outcome expectations, career interests, and perceived career barriers using the Multidimensional Inventory of Black Identity (MIBI). Support was found for the notion that racial ideology predicted these variables for African American college undergraduates. Quimby et al. (2007) examined the influence of social cognitive variables on African American adolescents' interest in environmental science. The sample consisted of 132 (57 male, 75 female) high school seniors enrolled in an urban scientific and technical high school from which $95 \%$ of graduates continued in higher education. Results found that investigative self-efficacy, outcome expectations, perceived barriers, support, and environmental concerns contributed significant variance to the prediction of interest in environmental science. Research by Gardner-Kitt and Worrell (2007) using the CRIS found that racial identity attitudes were significantly related with grade level among middle and high school students and suggested that research on racial identity attitudes with adolescents should incorporate age as a relevant variable. 
Betz and Hackett (2006) caution that self-efficacy and outcome expectations are cognitive appraisals of future performance and not trait concepts. Lent \& Brown (2006) echo this principle and state that "self-efficacy is perceived as a dynamic set of beliefs linked to a particular performance domain" (p. 15). The authors assert that attempts to measure social-cognitive variables be content or task-specific. In order to maintain consistency with this requirement in the proposed study, career related tasks typically associated with adolescence will be used to assess self-efficacy and outcome expectations. Examples include tasks such as "Knowing what information to provide about oneself during a job interview," or "Completing a job application correctly." The relationships hypothesized in this study bring together the theoretical principles of Nigrescence Theory and Social Cognitive Career Theory in order to examine the following research questions related to career development in African American males:

(1) Are racial identity attitudes, age, and the perception of racial barriers related to career self-efficacy for African American male adolescents, and if so, are racial identity attitudes the most influential of these variables?

(2) Are racial identity attitudes, age, and the perception of racial barriers related to career outcome expectations for African American male adolescents, and if so, are racial identity attitudes the most influential of these variables 


\section{CHAPTER II}

\section{REVIEW OF THE LITERATURE}

\section{Overview}

Six theories of identity development and reference group salience or orientation are discussed, including an analysis of the strengths and limitations of each theory with respect to their suitability for the current project. An overview of SCCT is also presented, along with four psychometric measures chosen to assess racial identity attitudes, self-efficacy, outcome expectations, and the perception of barriers.

\section{Choosing Between Racial Identity and Ethnic Identity as a Basis for Research}

Two categories dominate the relevant literature on identity development in minority adolescents: racial identity and ethnic identity. Defining the two categories, Phinney and Ong (2007) suggested that both race and ethnicity involve a sense of belonging, cultural values, and cultural behaviors, yet each differs in the ways they have been studied. Helms (2007) notes that while ethnic identity studies are largely concerned with an individual's values, traditions, or sense of belonging to a group, racial identity studies tend to focus on an individual's response to racism.

The other theoretical component fundamental to the study, Social Cognitive Career Theory (SCCT), is primarily concerned with the influence of self-efficacy, outcome expectations, interest, and other contextual variables on the career choice 
process. The current study conceptualizes identity development as a contextual variable, associated with the learning experienced as a result of race and contextual factors related to race. It seeks to analyze African American male adolescent attitudes associated with identity formation, the perception of career related barriers, the relationship of these attitudes to the subject's age, and the combined influence of these factors on self efficacy and outcome expectations. Perceived career barriers are defined by SCCT as obstacles that people anticipate will accompany the pursuit of specific goals. For the purposes of the current project, it was necessary to consider whether ethnic or racial assessment tools were best suited to psychometrically measure the current stage, status or attitude associated with the African American adolescent identity development process.

Much of the extant research on adolescent identity builds upon the concepts of Erikson's identity diffusion vs. achievement model (Erikson, 1959), and Marcia's fourstatus development process (Marcia, 1967). Using these models, Phinney (1989) conducted a research study that provided empirical support for a model of adolescent ethnic identity formation paralleling Marcia's four ego identity statuses. Phinney theorized that ethnic identity formation would consist of the following progression:

a. Identity diffusion - little or no exploration of one's ethnicity and no clear understanding of the issues.

b. Identity foreclosure - little or no exploration of one's ethnicity, but clarity about one's ethnic group membership. Feelings about one's ethnicity may be either positive or negative, depending on one's socialization experiences.

c. Identity moratorium - evidence of exploration, accompanied by some confusion about the meaning of one's own ethnicity. 
d. Identity achievement - evidence of exploration, accompanied by a clear, secure understanding and acceptance of one's own ethnicity.

Phinney's findings (1989) were significant in several ways. The study demonstrated support for the notion that ethnic identity development mirrored the process of ego identity development as theorized by Erikson and Marcia. It demonstrated that ethnic identity development was measurable across ethnic minority groups (indications of the stages were observed for Asian-American, Latino-American and African-American students) and gender groups. It also demonstrated that White adolescents did not experience this process, and that an achieved identity status was correlated with improved psychological functioning. Specifically, adolescents in the achieved status showed higher scores on self-evaluation, sense of mastery, social and peer interactions, and family relations. While each minority group demonstrated evidence of the developmental process that coincided with the theorized statuses, different issues were salient for the different ethnic groups in the resolution of ethnic identity. For African American male adolescents, a key area of concern for these young men was the possibility of future job discrimination.

As Phinney's 1989 study indicates, different issues have different salience for different groups at different times. While many issues faced by young African American males are not unique, the evidence of the disproportionate degree to which social, academic and economic disparities have negatively impacted this group has existed for some time (Taylor, 1995; Noguera, 2008; Wilson, 2009). Cokley (2007) suggests that when researching an individual's identity construction in response to an oppressive or highly racialized society, racial identity is a more appropriate construct than ethnic 
identity. Given the disproportionate degree of negative outcomes facing African American males, racial identity may be the more appropriate construct for the current project.

According to Carter (1995), different models of racial identity development are presented for different groups due to the different sociopolitical histories of each group and that these differences impact how racial histories are understood and dealt with. A sample of recent studies exploring the relationship between racial identity development and related areas of interest for African American youth is shown in Table 1.

\section{Table 1}

Recent Research on Racial Identity Development in Adolescents

$\begin{array}{lll}\text { Construct Authors Findings } & \text { Auting }\end{array}$

\begin{tabular}{lll}
\hline Psychological Functioning & Sellers, Copeland-Linder, & Racial discrimination \\
& Martin, \&Lewis, (2006) & was associated with \\
& lower levels of \\
& psychological \\
& functioning.
\end{tabular}

Psychological Adjustment Thomas, Townsend, \& Findings from the study Belgrave, (2003) supported the usefulness of combining racial identity and Afrocentric values into a single model of ethnic identification for African American children.

\begin{tabular}{lll}
\hline Risk and Protective factors & Caldwell, Kohn-Wood, & Results indicate that \\
Schmeelk-Cone, Chavous, & youths' endorsement of \\
\& Zimmerman, (2004) & ideological beliefs \\
& emphasizing being more \\
& like Whites related to \\
& more fears of being \\
& viewed as high \\
& achievers by peers \\
\hline
\end{tabular}


Table 1 (continued)

Recent Research on Racial Identity Development in Adolescents

Construct

Authors

Findings

Achievement

DeCuir-Gunby, (2007)

Common themes emerged regarding student's experiences, including problems with the elite context of the school, and the difficulty of negotiating African American identity.

\begin{tabular}{lll}
\hline Coping & Scott, (2003) & $\begin{array}{l}\text { Varying degrees of } \\
\text { resonance among } \\
\text { African American youth } \\
\text { from disparate social- } \\
\text { environmental contexts. }\end{array}$ \\
\hline Well-being & $\begin{array}{l}\text { Seaton, Sellers, \& } \\
\text { Scottham, (2006) }\end{array}$ & $\begin{array}{l}\text { Results supported the } \\
\text { assumption that } \\
\text { individuals in the } \\
\text { achieved status had the } \\
\text { highest levels of } \\
\text { psychological well- } \\
\text { being }\end{array}$ \\
\hline
\end{tabular}

The table illustrates evidence in the literature of attempts to understand African American adolescent behavior within the context of race. It is important to note that many other studies include categories of research existing within the broader construct of race - such as African American identity (Sanders-Thompson, 1992, 1995, 2001, 2003; Oyserman, Gant, \& Ager, 1995), oppositional identity (Ogbu, 2004; Battu, Mwale, \& Zenou, 2007), and racial ideology (Sellers, Shelton, Cooke, Chavous, Rowley, \& Smith, 1998). 
Ethnicity and race continue to be used interchangeably in many studies. Quite often, the only difference in research involving ethnicity or race is the choice of the term itself (Worrell \& Gardner-Kitt, 2006). Cokley (2005) suggests that it is theory that must be the driving force in making the determination to conduct studies within the context of race or ethnicity. Given the broad nature of extant research on identity development in African American youth, it is also critical that assessment tools are grounded in the theoretical perspectives that guide the intended research.

\section{Racial Identity Theory}

Psychological studies of African Americans have existed throughout American history, many rooted in ideologies of inferiority. Scientific studies of an individual's response to racism, within the context of self-hatred, began to be published in the 1930's and famously involved the work of Ruth and Eugene Horowitz, and Kenneth and Mamie Clark. In a seminal 1938 study, the Horowitz's used "objective measures of attitudes" (photographs) to demonstrate that children's attitudes about race developed as a result of community influence, with parents having the largest influence on these attitudes. Subsequent work with photographs by Ruth Horowitz (1939) found that group consciousness and group identity were basic to the understanding of the dynamics of attitude function.

Using a series of drawings with non-segregated and semi-segregated pre-school children, Kenneth and Mamie Clark were able to establish that children as young as 3 to 7 years of age had developed an awareness of racial difference, with knowledge increasing from year three to absolute stability at age 7 (Clark \& Clark, 1939, 1940, 1950). The studies also demonstrated that the majority of youth held a preference for 
white skin color and that their preferences were influenced by the degree of the darkness of their own skin. The following six theories build upon the pioneering work of the Horowitzs' and Clarks'.

\section{Nigrescence Theory Original (NT-O)}

Cross's 1971 original model of Nigrescence (a French word meaning "the process of becoming Black") described a five-stage process of development that theorized a progression from a desire to assimilate White culture, to Black pride and self-love. The stages in the original model are:

1. Pre-Encounter - An acceptance of the majority (White-European) world view, characterized by self-hatred, and a miseducated, "colonized" mindset.

2. Encounter - a personal, traumatic experience that creates enough cognitive dissonance to dislodge the old world view and create a readiness for change.

3. Immersion/Emersion - an intense, transitional period of experimentation with "Black" identity, characterized by a glorification of Blackness and a denigration of Whiteness.

4. Internalization - the individual moves from anxiety and insecurity with the new identity to confidence. The individual is able to accept Whites as individuals, distinguishing between good and bad people; and begins to focus on the systems of oppression.

5. Internalization-Commitment - the individual is self-loving, illustrating Black pride, and develops a dedication to justice for the Black community. 
Cross's original theory was formulated in the environment of the civil rights era of the late 1960 's to early 1970 's. At that time, Cross referred to the identity change process as "the Negro to Black conversion experience." In the 1991 revision to his theory, Cross acknowledged that reference group orientations that make use of the Negro label are "dead" (p. 189), and acknowledged a fundamental shift in the self-referent thought of most African Americans since the days of the civil rights era. He also described several attitudes as characteristic of various stages of the Black identity development process such as reactive coping or spotlight anxiety, ideas later expanded upon by Spencer et al. (1997), and Steele (1997) respectively.

Parham and Helms (1981) were the first to psychometrically operationalize Cross's original stages by introducing the Racial Identity Attitude Scale (RIAS), an instrument designed to measure racial identity attitudes as described by Nigrescence. In 1981, Parham and Helms used the RIAS in a study which found that Nigrescence attitudes were related to a subject's preference for counselor race. In 1985, using the RIAS, Parham and Helms found racial attitudes were related to the self-actualizing tendencies and affective states of Black college students. Subjects holding proWhite/anti-Black attitudes (pre-encounter) or pro-Black/anti-White attitudes (immersion) exhibited greater degrees of personal distress. Encounter attitudes were found to be positively related to self-actualization tendencies and negatively related to feelings of inferiority and anxiety. Parham later proposed that racial identity attitudes were likely to manifest in cycles, based upon various "encounters" associated with developmental stages of the life cycle (Parham, 1989). The author suggested that rather than discrete periods, the stages may in fact be continuous, suggesting that individuals may experience 
various stages simultaneously. However, consistent problems with the internal consistency of the RIAS and RIAS-B have raised concerns regarding its continued use in academic research.

\section{Critical Race Theory}

Delgado and Stefancic (2001) describe Critical Race Theory (CRT) as the study of the relationship between race, racism, and power. Founded in legal scholarship (Bell, 1973), CRT research has expanded to include the study of educational issues such as school discipline, tracking, curriculum, and achievement testing (Ladson-Billings \& Tate, 1995; Tate, 1997; Duncan, 2005; Williams, 2004). CRT is built upon the following tenets:

1. Racism is ordinary - it is the common, ordinary experience of most people of color in the U.S.

2. White-over-color ascendancy serves a material and psychological purpose.

3. Race is not objective, but a product of social construction. Society racializes different groups at different times.

4. Intersectionality - no person has a single, essential identity. An African American may also be gay, lesbian, Democrat, Republican, rural, or urban.

5. Voice-of-Color - through storytelling, people of color are able to articulate matters that Whites are unlikely to know.

Ladson-Billings et al. (1995), apply these principals to education in the following manner: 
1. For too many African Americans, the cause of their poverty and the condition of their schools are due to institutional and structural racism.

2. Addressing inequity through civil rights legislation does not offer permanent redress and often results in opportunities that current distributions of wealth render unaffordable and inaccessible to African Americans in poverty. The resulting dynamic elevates "Whiteness" to the status of property.

3. The voices of people of color are needed for a complete analysis of the educational system.

4. Current multicultural practices in education are trivial (eating other foods, listening to folk songs, dancing) and do not promote pursuit of fundamentally different conceptualizations of knowledge.

Using a semi-structured interview process, Decuir-Gunby (2007) used CRT to analyze the narratives of six African American students at a prestigious, private, collegepreparatory $(\mathrm{K}-12)$ school in the south. At the time of the study, the school was experiencing racial conflict resulting from a speech at a Black History Month event. The findings suggested that although the school's reputation for academic excellence offered the students greater opportunities in higher education, the environment at the school exposed the students to barriers they would face as a result of their race and social class. In another study, Duncan (2002) used CRT to analyze the schooling of African American male adolescents at a magnet school in the Midwest. Using an ethnographic design, Duncan concluded that mere access to schools held in high public regard did little to counteract the effects of structural racism and ignored the complexities involved with providing quality education to African American students. 
While each study may illuminate barriers specific to African American students, the lack of an experimental design in each study makes it difficult to generalize results or build systematically upon the findings. Underscoring this point, CRT's use of personal narratives has been criticized in the legal field as lacking an empirical focus (Posner, 1997). However, Duncan's (2005) critique of ethnocentric practices in education provides an important explanation of how narratives can broaden discussions of race and allow for new paradigms and ideas.

\section{Oppositional Identity Theory}

As discussed earlier, Cross (1971), described his Immersion/Emersion stage as an intense, transitional period of experimentation with "Black" identity, characterized by a glorification of Blackness and a denigration of Whiteness. A related area of research has explored the often controversial theory of the development of oppositional identities among African American adolescents and the negative impact that this identity development has on academic achievement. Fordham and Ogbu (1986) first theorized that what has emerged in segments of the Black community is a "cultural orientation that defines academic learning in school as 'acting White,' and academic success as the prerogative of White Americans" (Fordham \& Ogbu, 1986, p. 594). Significant challenges and criticisms to this premise exist among quantitative researchers (Cook \& Ludwig, 1997; Ainsworth-Darnell \& Downey, 1998). However, it is informative to the current project to understand the key concepts that underlie Ogbu's theoretical model.

Ogbu (2004) described collective identity as a people's sense of who they are, their "we-feeling", or "belonging". He suggests that the collective identity is maintained 
by the minority group's response to status problems - collective problems experienced by members of the subordinate group:

The minorities experience their mistreatment regardless of their individual differences in education and ability, in status, physical appearance, or place of residence. They know fully well that they do not have the option of membership in the dominant group; they also know that they cannot easily escape from their more or less ascribed membership in a subordinate and disparaged group...they respond as individuals in ways that reinforce their separate existence and collective identity. (p. 5)

Ogbu $(2003,2004)$ extended the findings from the Fordham and Ogbu (1986) study and detailed five strategies contemporary African Americans adopt in order to cope with majority-group demands to conform to certain attitudes and behaviors within White institutions and establishments:

1. Assimilation - Abandoning Black culture and dialect in order to behave and talk like Whites.

2. Accommodation Without Assimilation - Adopting majority-group cultural frames of reference and language when needed in order to succeed in school or other majority dominated institutions, without abandoning racial identity.

3. Ambivalence - Rejecting the belief that majority-culture frames of reference are an avenue to success. Concluding that barriers to success are fundamentally racial. 
4. Resistance or Opposition - Behaviors rooted in the belief that adopting majority norms will result in a loss of racial identity.

5. Encapsulation - Complete immersion in Black culture and dialect.

According to Ogbu (2003), the choice of which strategy to adopt is not made in isolation. In his studies of African American adolescent's academic behaviors, Ogbu details his observations of social sanctions or peer pressures against accommodation strategies or "acting White." These pressures became evident during middle school years and reached their peak during high school years, timeframes that would logically coincide with Erikson's "time of crisis."

Ogbu's theory has received a good deal of scrutiny and criticism. Downey and Ainsworth-Darnell (2002) found that, contrary to oppositional theory, high-achieving African American students were very popular among their peers. Using data from the National Education Longitudinal Study (1994), Cook and Ludwig (1997) found that peer pressure did not reduce the level of effort and performance of African American students. Spencer et al. (2001) critique Ogbu's theory and report:

The theoretical assertion that a positive achievement orientation as held by African American youth is associated with a White cultural identity is challenged by empirical findings. Specifically, the "acting White" theory as presented by Fordham and Ogbu (1986) and made highly visible by the national media, suggests that youth of color, and particularly African Americans, do not value education. The view itself contributes to cultural stereotyping in its failure to acknowledge the role of solidly entrenched social stereotyping in the school adjustment and coping requirements of African Americans. (p. 22) 
In addition to this critique, there are also no examples in the literature operationalizing the other four coping strategies advanced by Ogbu beyond Oppositional Attitudes (Assimilation, Accommodation Without Assimilation, Ambivalence and Encapsulation). Still, many critics acknowledge that Ogbu's ideas have advanced the understanding of ethnic differences in academic achievement (Spencer \& Harpalani, 2008). And while researchers have challenged the degree to which Black student's oppositional attitudes have a negative impact on achievement, most accept the assumption that racialized attitudes exist among African American adolescents (Harris, 2006; Peterson-Lewis \& Bratton, 2004; Bergin \& Cooks, 2002).

\section{Phenomenological Variant of Ecological Systems Theory (PVEST)}

Spencer's Phenomenological Variant of Ecological Systems Theory ( PVEST) is a lifespan process of normative human development that the author proclaims is applicable across ethnic groups (1997). Spencer and Harpalani (2008) describe PVEST as "a heuristic device that can account for the differences in experience, perception, and negotiation of stress and dissonance, or lack thereof" (p. 230 in Minority Status, Oppositional Culture, \& Schooling, Ogbu, 2008)). With respect to African American adolescents, Swanson, Spencer, Dell'Angello, Harpalani, and Spencer, (2002), report: Myriad conceptual flaws and misunderstandings characterize scholarship on Black youth: deficit-oriented assumptions, lack of developmental perspective, inappropriate avoidance of racial and ethnic themes, and the absence of a normative and comprehensive theoretical framework. (p. 74)

To address this lack of framework, Spencer (1997) conceptualizes a system of normative development that consists of: 
1. Net Vulnerability - prior experiences and coping outcomes that may potentially pose challenges during an individual's development. It denotes the tension between risk contributors (i.e., poverty, discrimination, racially stereotyped expectations) and protective factors.

2. Net Stress Engagement - actual experiences that challenge an individual's wellbeing. Whether this experience is actualized or inferred, it must be negotiated.

3. Reactive Coping Methods - strategies employed to reduce dissonance-producing situations.

4. Emergent Identities - stable coping responses that, coupled with self-appraisals, define how individuals view themselves within and between their various contexts of development (e.g., family, school, neighborhood).

5. Stage-specific coping outcomes - Identity-linked perception, self-appraisal and behavior that can be productive or adverse.

Using longitudinal data and Cross's Nigrescence model as a framework for normative African American adolescent development, Spencer et al. (2001) reported that youth with the highest salience for "White" attitudes (Pre-encounter) were more likely to have low levels of achievement and low self-efficacy scores. The authors also report that students at the Immersion stage are also more likely to be low achievers and are most likely to use accusations of "acting White" toward higher achieving students as a means of reactive coping.

PVEST has been used to study identity development and various contextual factors influencing African American development. Examples include national and civic 
attachment (Spencer, 2011), coping and psychological well-being (Spencer, Fegley, \& Harpalani, 2003), and academic support (Youngblood \& Spencer, 2002). However, although identity development is an integral part of the PVEST framework, it is not a theory specific to African Americans. Spencer and Markstrom-Adams (1990) explain:

The complexity of identity formation may increase as a function of color, behavioral distinctions, language differences, physical features, and longstanding, although frequently unaddressed, social stereotypes. Further, these factors operate, to varying degrees, between minority groups. For example, the issue of color may be more salient for African Americans and American Indians than it is for other minority groups (e.g., Hispanic and Asian). The persistence of color stereotyping and color bias results in the potential for unique identity formation processes for both monoracial and biracial youth (i.e., children of interracial unions). (p. 290).

Traditional models of identity development are typically conceptualized developmentally, as stage or status progressions (Erickson, 1959; Cross, 1971; Marcia, 1980; Cross, 1991). The PVEST model differs from traditional racial or ethnic models of identity development in that it explicates a framework for identity development by accounting for contextual factors that will influence that development in positive or negative ways. This difference complicates the generalization of PVEST research, as the findings are highly context dependent. This is illustrated by the use of Nigrescence theory by Spencer et al. (2001) to define racial identity development. If racial identity is to be situated within a contextual framework, it seems more prudent for the current 
project to use a framework that is specifically related to career theory and offers a wider empirical base.

\section{Stereotype Threat}

Stereotype threat research operates on the hypothesis that widely-known stereotypes about an individual's reference group create an anxiety in the individual about anything he or she may do that would lend credence or plausibility to the stereotype. The resulting anxiety is theorized to be of such intensity as to diminish performance to a level below that of which the individual is actually capable. In performance domains that are seen to be indicative of intellectual ability, studies indicate that stereotype threat has a diminishing effect on the performance of African American students (Steele \& Aronson, 1995). Steele (1997) reports the following observations about stereotype threat:

1. It is a general threat, not tied to the particular psychology of stigmatized groups. It affects the members of any group about whom negative stereotypes exist.

2. The threat is activated across group or individual settings. It is the relevance of the stereotype within a particular setting that is most salient.

3. The type and degree of the threat varies from group to group, and across settings within the group.

4. To experience stereotype threat, one need not believe in the stereotype, nor even be concerned that it is true of oneself. The concern or "pressure" is suspecting or confirming others belief in the stereotype. 
5. Overcoming the stereotype in a particular setting does not automatically generalize to another setting, thus the threat can be everlastingly recurrent.

Support for these observations was demonstrated by research on women and math ability (Steele, 1997), and White men and math ability (Aronson, Lustina, Good, Keough, Steele, \& Brown, 1999). It should be noted, however, that measures used to assess stereotype threat vary widely.

Since the current study focuses on the early-stage career decisions of adolescents, it is important to establish empirical evidence of stereotype awareness among adolescents. McKown and Weinstein (2003) conducted research on the development and consequences of stereotype awareness among children aged 6 to 10. The study found that ability to infer an individual's stereotyped beliefs increased dramatically with age: $18 \%$ at age $6,39 \%$ at age $7,64 \%$ at age $8,83 \%$ at age 9 , and $93 \%$ at age 10 (p. 504). In addition, the study also found that children from stigmatized groups (African American and Latino) were more likely than children from non-stigmatized groups to be aware of broadly held stereotypes: $15 \%$ (stigmatized group) vs. $7 \%$ (non-stigmatized group) at age $6,28 \%$ vs. $14 \%$ at age $7,46 \%$ vs. $27 \%$ at age $8,65 \%$ vs. $44 \%$ at age 9 , and $80 \%$ vs. $63 \%$ at age 10 (p. 505).

Research by Evans, Copping, Rowley, and Kurtz-Costes (2011), found that for African American seventh and eighth graders, negative racial stereotypes were more relevant to academic self-concept for boys than for girls. Arbuthnot (2009) also studied middle school African American boys and found that the high-achieving boys were more susceptible to stereotype threat than the middle or low achieving students. Cokley (2011) found that for African American male high school students, the correlation between 
academic self-concept and GPA decreased sharply as age increased, suggesting that disidentification may become a group norm for older students. He also found that the students for whom race was more salient had lower GPA's.

Steele (1999) posited the following rhetorical questions for the future study of stereotype threat: Does race become a boundary for experiences, emotions and relationships? Do African American students grow weary of the "attributional ambiguity" and the extra vigilance required by being on the receiving end of negative stereotypes? To reduce the resulting stress, do African American students learn to care less about the activities and situations that bring it about? Is this psychic adjustment of "disidentification" supported by other members of the stereotype-threatened group - even to the point of becoming a group norm? These are important questions. However, when compared with other Black racial identity theories, stereotype threat is relatively narrow in scope, describing only one emotional response to perceived racism. As such, it may not offer the range of information that could be uncovered by a broader definition and analysis of identity for the proposed study.

\section{Nigrescence Theory Expanded (NT-E)}

In response to questions from the academic research community concerning the validity of the developmental aspects of Nigrescence, Cross and Vandiver (2001) further revised Nigrescence theory by describing the socialization and "re-socialization" processes associated with a lifespan perspective of racial identity, with the goal of establishing Nigrescence "within the mainstream of developmental literature" (p. 243). Each of the eight attitudes falls under the heading of one of three of Cross's original stages (1971). They are: 
Pre-Encounter Attitudes

1. Assimilation - Individuals who are pro-American and do not view being African American as being important.

2. Miseducation - Individuals who endorse the negative stereotypes of the African American community (lazy, criminal, etc.)

3. Self-Hatred - Individuals who have a personal dislike of being African American. Immersion-Emersion Attitudes

1. Intense Black Involvement - Extreme acceptance of anything African American as good.

2. Anti-White - Individuals with strong feelings of hatred and disdain for all White people

Internalization Attitudes

1. Nationalist - An individual who stresses an Afrocentric perspective of himself and the world. (this subscale was later renamed "Afrocentric")

2. Biculturalist - An individual who embraces Afrocentric culture as well as mainstream culture.

3. Multiculturalist - An individual who embraces a wide range of cultures.

The lifespan perspective described the likelihood of developing racial attitudes along six "sectors" of development: (1) infancy and early childhood, (2) pre-adolescence, (3) adolescence, (4) emerging adulthood and (5) adulthood. The authors also include Parham's (1989) recycling stage as a sixth developmental sector. It is in this revision, 
that Nigrescence first explicates a path to internalization attitudes for adolescents without a "re-socialization" or "conversion" experience. However, Cross and Vandiver (2001) point out that their interpretation of adolescence (Sector 3) describes the great majority of Black youth examining and struggling with issues of race and Black culture.

Cross and Fhagen-Smith's (2001) revision of Nigrescence theory led to the development of the Cross Racial Identity Scale (CRIS), jointly developed by Vandiver, Fhagen-Smith, Cokley, Cross, \& Worrell, (2001). Using factor analysis, two subscales (Biculturalist, Intense Black Involvement) were dropped and the remaining six subscales were used to create the scale. Each attitude measured by the CRIS is represented by a subscale that is considered to be unidimensional. The researchers report that the reliability of the subscale is appropriately tested by the use of Cronbach Alpha scores. Sample items from each subscale are presented in Table 2.

\section{Table 2}

\section{Sample Questions from the CRIS Subscales}

Pre-encounter Assimilation (PA): "I am not so much a member of a racial group, as I am an American" Pre-encounter Miseducation (PM): "Blacks place more emphasis on having a good time than on hard work"

Pre-encounter Self-Hatred (PSH): "Privately, I sometimes have negative feelings about being Black" Immersion-Emersion Anti-White (IEAW): "I have a strong feeling of hatred and disdain for all White people"

Internalization Afrocentricity (IA): "I see and think about things from an Afrocentric perspective" Internalization Multiculturalist Inclusive (IMCI): "As a Multiculturalist, I am connected to many groups (Hispanics, Asian-Americans, Whites, Jews, gays, and lesbians, etc.)" 
The attitudes measured by each subscale of the CRIS represent both cognitive and affective approaches to an individual's reference group orientation (Simmons, Worrell, \& Berry, 2008). Cross has long maintained a developmental framework for Nigrescence $(1971,1991)$. More recent versions of the theory continue this theoretical perspective and suggest that traditional socialization, resocialization, or recycling are necessary experiences for the development of a well-formed identity (Cross \& Vandiver, 2001; Cross \& Fhagen-Smith, 2001). The researchers suggest that most African American children will enter adolescence with an identity that has been primarily shaped by the influences of parents and significant others. They further theorize that adults will form a stable identity either through formative socialization, or an encounter that triggers an identity conversion experience (Cross \& Vandiver, 2001). Enhancements or modifications to this identity (recycling) will occur throughout adulthood (Cross \& Fhagen-Smith, 2001).

In an attempt to explore the developmental nature of the expanded Nigrescence theory, Worrell (2008) reports establishing a profile of CRIS scores for three separate age groups: adolescent (middle and high school students), emerging adult (college students), and adults. Contrary to Nigrescence's theoretical propositions on adolescent development and socialization (Cross, 1971, 1991; Cross \& Fhagen-Smith, 2001), the patterns of mean subscale scores for each age group were quite similar as shown in Figure 1. 


\section{Figure 1}

\section{Mean Subscale Scores, Worrell 2008 Sample}

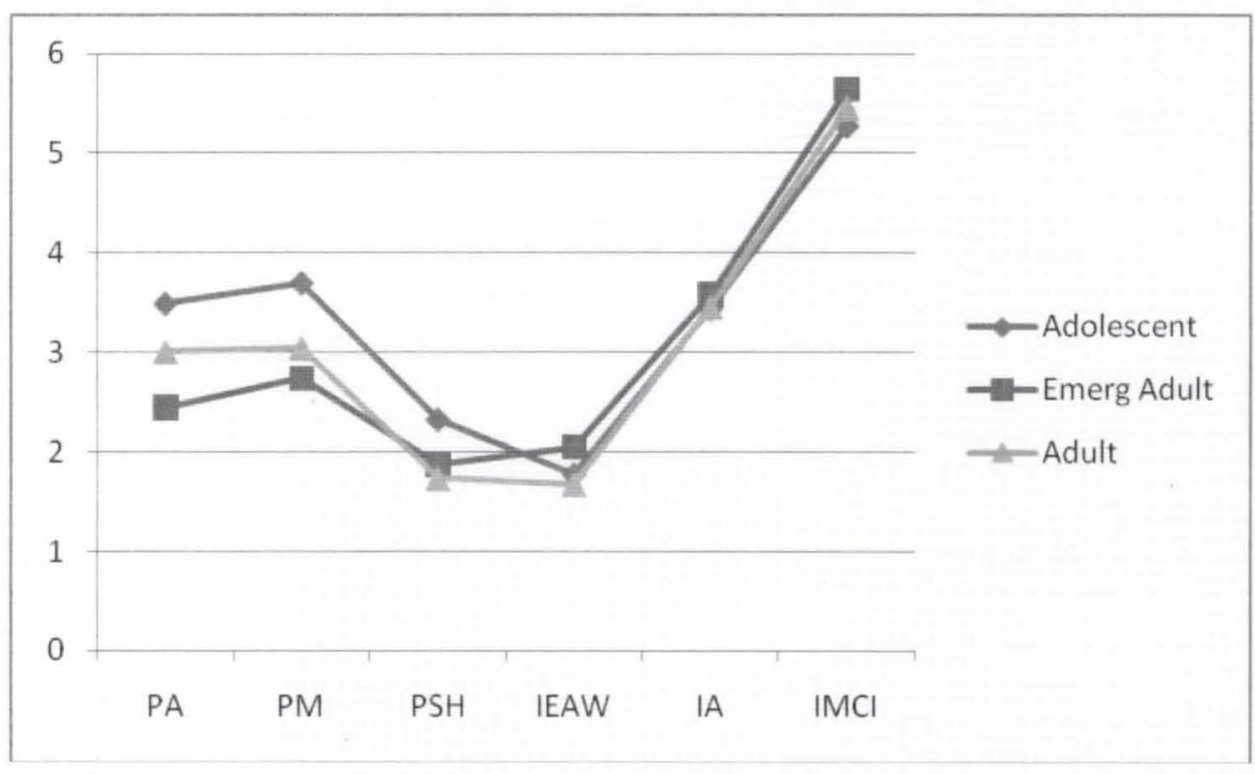

Figure 2 illustrates six Nigrescence profile clusters reported utilizing the CRIS and multivariate cluster analysis (Worrell, Vandiver, Cross, \& Fhagen-Smith, 2006). 
Figure 2

Cluster Analysis of Racial Identity Profiles (Worrell et al. 2006)

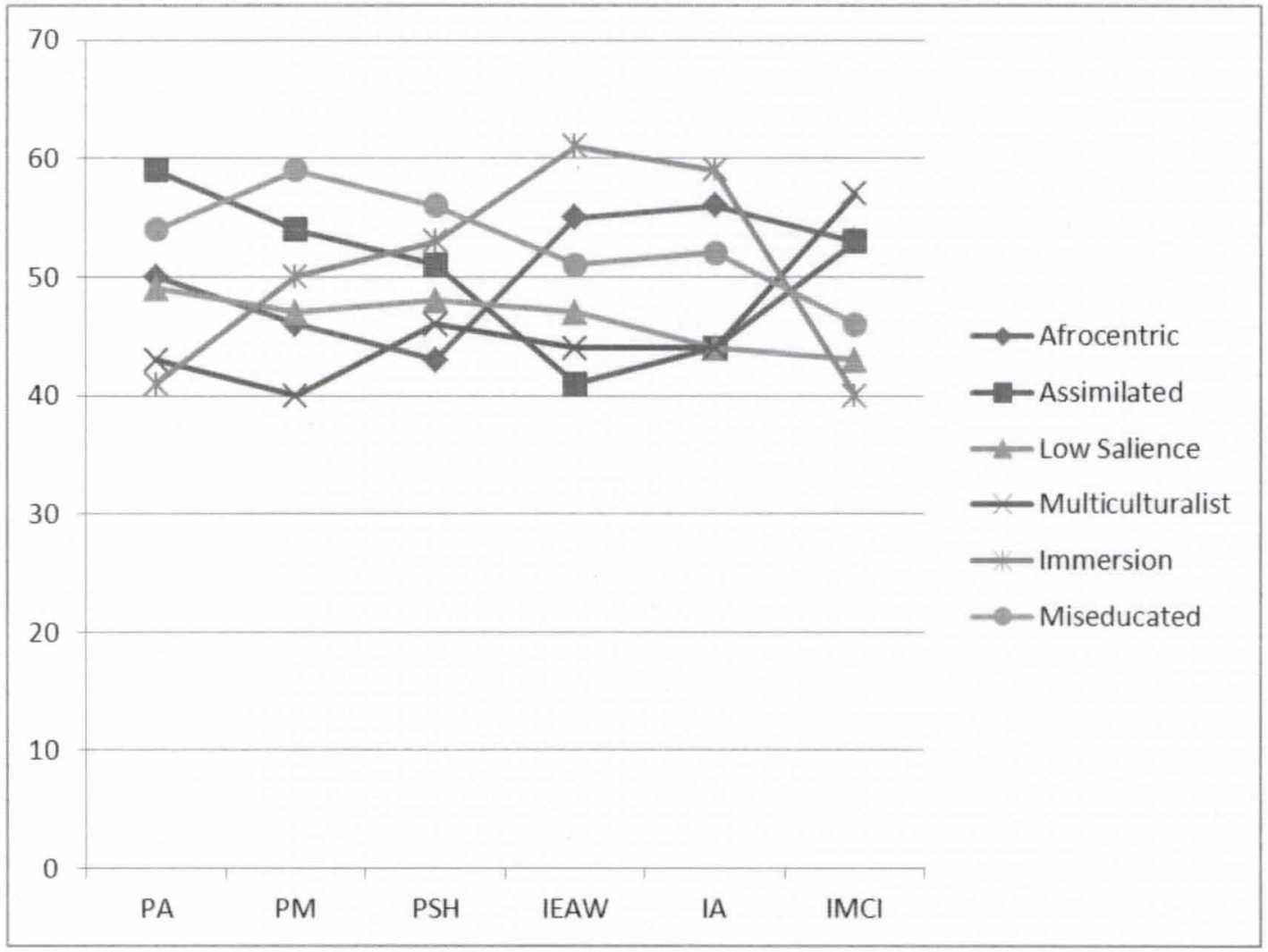

According to Worrell et al. (2006) the characteristics associated with the cluster profiles include:

(1) Assimilated-Individuals in the assimilation clusters see themselves as American rather than African American. They have accepted the negative stereotypes of African Americans but do not apply these stereotypes to themselves.

(2) Miseducated Variant - This profile describes a group of people whose racial identity is strongly influenced by negative stereotypes of African Americans. 
Although their Afrocentric attitudes are above average, the dominant themes for this group are Preencounter, Miseducation, Assimilation, and Self-hatred.

(3) Low Race Salience - these individuals seem to avoid dealing with or thinking about issues of race and do not even take a strong position on being American versus African American.

(4) Immersion - This profile reflects individuals who see themselves as African Americans (high scores on the Afrocentric subscale) but who are still dealing with issues of Miseducation and Self-hatred. These individuals also reject multiculturalism strongly.

(5) Afrocentric - These individuals are low in self-hatred and reject the negative stereotypes about Blacks.

(6) Multiculturalist - These individuals reject negative stereotypes about both Blacks and Whites and have a strong Black identity alongside the willingness to work with other groups.

Cross's theory remains the most thoroughly researched theory of Black racial identity in the literature (Cokley, 2002).

\section{Racial Identity and Psychometric Assessment}

Numerous examples in the literature provide guidance for the formulation and development of testable hypotheses with respect to Black racial identity development. As stated earlier, research in this area often falls into two categories: ethnic identity studies and racial identity studies. Recent literature further clarifies the distinctions necessary for accurate assessment of these constructs. Cokley (2007) discusses the 
Multigroup Ethnic Identity Measure (MEIM), the Ethnic Identity Scale (EIS), the Racial Identity Attitude Scale (RIAS-B), and the Cross Racial Identity Scale (CRIS). The author reports that although the MEIM and the RIAS-B have been the most frequently used scales for measuring ethnic identity and racial identity respectively, psychometric studies suggest that the scales are problematic. Principal factor analysis with the MEIM results in scoring methods that are inconsistent with Erikson's original conception of identity resolution in that a total score combines separate stages of the process (Cokley, 2007; Byars-Winston, 2006). As for the RIAS-B, beyond having consistent problems with reliability, the RIAS-B is based on a theory that Cross (1991) has since revised. The EIS and the CRIS were specifically developed to address these psychometric issues.

Cokley (2007) recommends that researchers interested in Black racial identity would be best served by using the CRIS. Phinney and Ong (2007) agree that for specific aspects of group identity for particular groups, racial identity measures are better suited for research purposes. Vandiver, Cross, Worrell, and Fhagen-Smith (2002) found support for the validity of the CRIS and that the subscales were not meaningfully linked to social desirability or personality traits. Gardner-Kitt and Worrell (2007) examined the reliability and validity of the CRIS and concluded that it was an appropriate measure for use with adolescents.

\section{Social Cognitive Career Theory}

Derived principally from Albert Bandura's Social Learning Theory (1977), SCCT subscribes to Bandura's theory of triadic reciprocality - concurrent interaction between human cognitions, human behavior, and contextual variables. According to SCCT, the key element of this process is the concept of self-efficacy. In 1982, Bandura wrote: 
Self-efficacy judgments, whether accurate or faulty, influence choice of activities and environmental settings. People avoid activities that they believe exceed their coping capabilities, but they undertake and perform assuredly those that they judge themselves capable of managing. (p. 123)

According to Bandura (1982), self-efficacy is based on four sources of information:

1. Enactive Attainments - the most influential source of knowledge; if we repeatedly succeed at tasks, our sense of efficacy increases. If we repeatedly fail, our efficacy decreases.

2. Vicarious experience - if we see similar others succeed at a task, we infer that we can too.

3. Verbal persuasion - When someone convinces us we can perform a task, we usually do better at it, usually because we expend more effort.

4. Physiological cues - Some may interpret fatigue or anxiety as signs that a task is too difficult. However, people often react differently to the same bodily cues. Bandura (1982) described self-efficacy as the determinant of how much effort people will expend and how long they will persist in the face of obstacles. A metaanalysis by Multon, Brown, and Lent (1991) located 68 studies using self-efficacy as the qualifying term. Of those, 39 measured the relationship of self-efficacy to performance or persistence. The results of the analysis showed that effect size estimates $(r=.38$ for performance, and $\mathrm{r}=.34$ for persistence) suggested that "across various student samples, criterion measures and designs, self-efficacy beliefs accounted for approximately $14 \%$ of the variance in student performance, and $12 \%$ of the variance in student persistence" ( $\mathrm{p}$. 
34). In 1999, Albert and Luzzo proclaimed self-efficacy to be the central defining element of personal agency. Accordingly, Bandura, Barbaranelli, Vittorio, and Pastorelli (2001), demonstrated that children's perceived efficacies are a more salient predictor of occupational aspirations than actual academic achievement.

Lent, Brown, and Hackett (2000) identify outcome expectations as another component of the personal-cognitive dynamic at work in triadic-reciprocality paradigm. In discussing outcome expectations, the authors are careful to distinguish between distal future outcomes and more proximal outcomes:

We think this proximal-process versus distal-outcome distinction is potentially important for several reasons. In particular, it acknowledges that people do not simply pursue a career because of its ultimately foreseen payoffs. Rather, they also consider the conditions they are likely to face in its pursuit (e.g., "medical school will be impossibly hard on my relationships and my bank account"), among other important factors, like self-efficacy regarding the occupation's requisite skills. Thus, two individuals with similar distal-outcome expectations regarding a career in medicine may hold quite different process expectations about the proximal barriers and supports they would encounter in pursuing this goal. (p. 15)

According to SCCT theory, the acquisition of self-efficacy, outcome expectations, development of career related interests, and the formation of provisional career goals are prominent tasks of elementary and middle school years, and these goals are revisited and refined in high school (Lent, Hackett, \& Brown, 1999). Specifically, the authors 
highlight six inter-related processes which manifest at various stages of development during this timeframe:

1. Acquisition of positive, yet realistic self-efficacy and outcome expectations.

2. Development of academic and career interests.

3. Formation of linkages between interests and career-related goals.

4. Translation of goals into action.

5. Skill development and remediation of performance problems.

6. Negotiation of social supports and barriers that affect the pursuit of career options (p. 300).

Depending upon the appropriateness of the design and the accuracy of the assessment tools, SCCT may offer the opportunity to explore adolescent factors relevant to the career development of African American males.

\section{Contextual Barriers as a function of Race}

Constantine (2002) suggests that race, ethnicity, gender, and social class represent "salient cultural group memberships, and that reality is constructed in part, depending upon these memberships" (p. 210). In 2005, she and other researchers examined contextual factors unique to African American adolescent's career decisions within the SCCT framework (Constantine et al., 2005). One hundred and fifty one African American students ( 88 girls, 63 boys) were studied regarding career related perceptions and attitudes. Instruments included a demographic questionnaire, a perception of barriers scale, a parental support scale, and a career decision inventory. Cronbach Alphas of .76 or higher were computed for each scale. Support was found for the importance of 
considering perceived occupational barriers in the career decision-making process of African American adolescents.

Other evidence supports using this approach. Rollins and Valdez (2006) explored the effect of perceived racism on self efficacy and career task readiness in African American adolescents and found that children who perceived a higher degree of racism reported a higher self-efficacy for career decision making, but a lower efficacy for task readiness. Ali and Sanders (2006) researched the role of self efficacy, parental education, and parental support on the college expectations of rural Appalachian high school students, finding that parental support predicted college expectations.

Kerpelman and Mosher's 2004 study on the effect of self-efficacy, control and responsibility, and identity development on the future orientation of rural African American adolescents is also instructive. Along with a finding that self-efficacy was strongly correlated with future orientation, the authors' hypothesis that higher levels of identity development will predict higher levels of future education orientation and future career orientation was also supported. Further analysis also revealed that the relationship between identity development and future orientation among African American adolescents was moderated by gender.

\section{SCCT and Psychometric Assessment}

Lent and Brown (2006) make several suggestions for the conceptualization and assessment of Social Cognitive constructs in career research. With respect to selfefficacy they warn:

When conceived at the most global level, self-efficacy loses its context and domain specificity, and may overlap considerably with trait-like variables, 
whereas at its most specific levels, there is a risk of studying phenomena that may be theoretically interesting, but lack clear relevance to practical vocational applications. (p. 19-20).

Thus it is necessary to choose a particular level of specificity and generality when assessing self-efficacy. For example, when using Holland-themed careers, the most global level of specificity might be the Investigative theme. This would increase in specificity to scientific self-efficacy, to math self-efficacy, to algebra self-efficacy. Given that adolescents in the sample for the current project are as young developmentally as seventh grade, a global level of specificity was chosen for the design.

Outcome expectations differ from self efficacy in that rather than referring to an assessment of personal ability, they refer to what one expects to receive after attaining one's goal. These expectations may be positive or negative, thus it is important to consider what effect the negative or positive formulations of participants outcome expectations will have on the design of the experiment.

Albert and Luzzo (1999) remind researchers that individuals who possess high levels of career-related self efficacy and high outcome expectations for the rewards of a particular career may still avoid selecting that career if they perceive insurmountable barriers. Conversely, individuals with high coping efficacy may engage in efforts to overcome the perceived barriers. Therefore, it is critical to carefully target the particular efficacy or outcome expectation variables of interest (p. 435).

Lent and Brown (2006) point out that an SCCT approach to the study of contextual barriers focuses primarily on the proximal obstacles that people anticipate will accompany their pursuit of career goals. Racial identity development is fundamentally 
concerned with barriers anticipated as a function of race. SCCT allows that these barriers may be either objective or perceived. This is an important component of the model, as the current project seeks to measure adolescent identity development, which according to Cross (2001), is as likely to be influenced by perception as experience.

Lent, Brown, and Hackett (2000) suggest that SCCT's environmental hypotheses have received limited inquiry due in part to a lack of theory-derived measures for assessing contextual factors. Three tools specifically designed to assess SCCT constructs with adolescent populations were selected for the current study. McWhirter (1997) developed the Perception of Barriers Scale (POBS), and found ethnic and gender differences in perceived career barriers among high school students (females anticipated more barriers than males, and Mexican American students anticipated more barriers than White students). McWhirter, Rasheed, and Crothers (2000) developed the Vocational Skills Self Efficacy Scale (VSSE) and the Vocational Outcomes Expectations Scale (VOE) for high school students as well. Using a nonrandomized, within-subjects, crossover design, they found that the self-efficacy and outcome expectations for a sample of high school sophomores were related to a career education class. A health education class was used as the control condition.

Further work on the development of an outcome expectation scale continued with Paa and McWhirter's study of high school students and the factors influencing outcome expectations (2000). The study found girls' expectations were more likely to be influenced by mothers, female peers, and female teachers. In 2001, Luzzo and McWhirter extended this research to include the effect of sex and ethnic differences on career-related barriers and levels of coping efficacy, finding that ethnic minorities 
perceived more career barriers, and exhibited less coping efficacy. Finally, Ali et al. (2005) found that for a sample of lower SES ninth graders, self-efficacy predicted outcome expectations, but the perception of barriers did not account for any variance in outcome expectations for the group.

\section{Summary}

This literature review summarized the extant research on the development of racial identity attitudes in African American adolescents, and the relationship between these attitudes and an adolescent's commitment to educational and career options. The literature review also encompassed research related to racial differences in the perception of barriers to educational and career pursuits. Social Cognitive Career Theory, a theory of career decision making that encompasses the specific variables of self-efficacy, outcome expectations, and contextual barriers was described and presented as a theoretical foundation for the study. Based on the review of the current literature, research hypotheses were developed to test the relationships among racial identity attitudes, the perception of barriers, and age, and to explore the relative influence of these variables on self efficacy and outcome expectations in adolescent African American males. 


\section{CHAPTER III}

\section{METHOD}

The proposed study is designed to analyze early-stage career behavior among African American male adolescents by exploring the effects of racial identity attitudes, the perception of career barriers, and age on the Social Cognitive Career Theory (SCCT) choice variables of self-efficacy and outcome expectations. The research questions are: (1) Are racial identity attitudes, age, and the perception of racial barriers significantly related to the career-related self efficacy of African American male adolescents?

(2) Are racial identity attitudes, age, and the perception of racial barriers significantly related to the career-related outcome expectations of African American male adolescents?

\section{Approval}

Approval to conduct this research project was obtained from the University of Louisville Institutional Review Board on May 20, 2010. The study was closed following the collection of all data.

\section{Participants}

A convenience sample of 124 male African American middle and high school students were selected from two public school districts and two charter schools in a large Midwest metropolitan area. Initially, a total of 200 students were selected by school 
personnel and were provided with consent and assent forms to obtain permission to participate in the study. One hundred and twenty four students returned the necessary forms and were included in the study. Based upon the research of Ogbu (2003) and Gardner and Worrell (2007), it was expected that racial identity attitudes would mature as students got older. Students were selected from the $7^{\text {th }}$ through $12^{\text {th }}$ grades. Participants ranged in age from 12 to 19 with a mean age of $16.31(S D=1.40)$. The distribution of ages was affected by the difficulty in obtaining parental permission from the freshman and middle school aged youth.

\section{Setting}

The researcher collected data in either a classroom or library setting during school hours. The schools included two public high schools, one public middle school, one public freshman school, and two charter schools. At the public schools, data collection took place in the library, and school personnel were assigned to monitor the sessions. At the charter schools, the researcher was provided with a classroom and was unaccompanied during the session. Regardless of the school setting, no one other than the researcher handled the student's data.

\section{Procedures}

Prior to the administration of the scales used to measure the research variables, the researcher explained the purpose of the study, the student's right to confidentiality, and the student's rights to decline to participate at any time. During the administration of the scales, the researcher answered all questions posed by participants. As anticipated, some constructs incorporated in the CRIS (such as "Afrocentric" or "affirmative action") required explanation. The same definitions and answers were provided across 
participants. Participant responses to the surveys were identified with a numerical code based on the school attended. Student names were not used to identify a completed packet. Answers to all questions are maintained by the researcher only, and no answers were shared with the school. No information maintained by the researcher identifies participants by name or school.

Each participant was given a $\$ 5$ McDonald's gift certificate upon collection of the data. A lottery drawing for a two tickets to a local amusement park and a professional sports ball game was also held at the completion of the project. Students and parents were informed that they would be given the opportunity to process the experience with the researcher if they desired to do so. No requests for this offer were received.

\section{Measures}

Each student was administered the Vocational Skills Self-Efficacy Scale (McWhirter, Rasheed, \& Crothers, 2000), the Perception of Barriers Scale (McWhirter, 1997), the Vocational Outcome Expectancy Scale - Revised (McWhirter \& Metheny, 2009), and the Cross Racial Identity Scale (Worrell, Vandiver, \& Cross, 2004). Each scale has been previously used with adolescents.

\section{Vocational Skills Self Efficacy Scale (VSSE)}

The VSSE is a 37 -item measure designed specifically to assess secondary students' confidence in their ability to complete specific tasks associated with choosing and pursuing a career. Items were derived from the secondary-level vocational skills guidelines mandated by the state in which the original study was conducted (McWhirter et al., 2000). The guidelines specify skills youth should possess upon graduation from high school. Respondents rate confidence in their ability to perform tasks such as 
"Complete a job application correctly," The instrument uses a 9-point Likert scale ranging from "No confidence at all" to "Completely confident. A Cronbach's Alpha of .97 and test-retest reliability of .68 (at a nine week interval) for a sample of 166 high school sophomores was reported by McWhirter et al. (2000). In the McWhirter et al. (2000) study, the researchers correlated VSSE scores with the Career Decision Making Self Efficacy Scale (Betz \& Taylor, 1994) as an indicator of convergent validity. Correlations ranged from .84 to .91 , indicating good convergent validity. Cronbach's Alpha for the current sample was .93.

\section{Perception of Barriers Scale (POBS)}

The Perception of Barriers Scale (POBS) was designed for use with high school and junior high school-aged children to detect ethnic and gender differences in the perception of career and educational barriers (McWhirter, 1997). For the purpose of the current study, only the career barriers, pre-college educational barriers, and general perception items from the original scale were used. Items 23 and 24, designed to assess the ability to cope with perceived barriers, were dropped from the analysis. Including the questions in the analysis would have added a ninth variable and would have violated the limits of adequate power for a regression with the available sample size. Two additional items (questions 7 and 8) were not used to compute the POBS. McWhirter (1997) recommends omitting these items (questions regarding the likelihood of being hired) because of very low item/total scale score correlations. Participants responded to the sentence stem, "In my future career, I will probably..." on a Likert scale ranging from 1 (Strongly disagree) to 5 (Strongly agree) for items describing discriminatory and 
educational career barriers. Cronbach's Alphas for the selected items in the McWhirter (1997) study were reported at .89. Cronbach's Alpha for the current study was .81 .

\section{Vocational Outcome Expectancy Scale - Revised (VOE-R)}

The VOE-R (McWhirter \& Metheny, 2009) is a 12-item measure designed to assess an individual's imagined consequences of pursuing a vocational career. Student's respond by rating items such as "I will be successful in my chosen career" on a 4-point Likert scale, ranging from "strongly disagree" to "strongly agree." Cronbach's Alpha has previously been reported from .90 with high school seniors to .92 for a ninth grade sample (Ali, McWhirter, \& Chronister, 2005; Metheny, McWhirter, \& O’Neil, 2008). Test-retest reliability with a sample of high school sophomores at nine weeks was reported at $r=.59$ (McWhirter et al., 2000). Cronbach's Alpha for the current sample was calculated at .96 .

\section{Cross Racial Identity Scale (CRIS)}

The CRIS is a measure of African American racial identity attitudes based on the revised Nigrescence model proposed by Cross (1991). The instrument measures the degree to which an individual holds each of six racial identity attitudes:

Pre Encounter Assimilation (PA) - Attitudes that are pro-American and do not view being African American as being important.

Pre Encounter Miseducation (PM) - Attitudes that endorse the negative stereotypes of the African American community.

Pre Encounter Self-Hatred (PSH) - Attitudes that reflect a personal dislike of being African American. 
Immersion-Emersion Anti-White (IEAW) - Attitudes reflecting strong feelings of hatred and disdain for all White people.

Internalization Afrocentric ( $I A)$ - Attitudes that stress an Afrocentric perspective of the individual and the world.

Internalization Multicultural Inclusive (IMCI) - Attitudes embracing a wide range of cultures.

Responses are measured on a seven-point likert scale ranging from "Strongly disagree" to "Strongly agree." Vandiver, Cross, Worrell, and Fhagen-Smith (2002) used factor analysis to test the validity of the attitudes associated with the new Cross Racial Identity Scale (CRIS). The analysis of the six subscales suggests that the subscales are not significantly correlated and do not present problems with multicollinearity for the use of regression analysis (Vandiver et al., 2002; Simmons, Worrell, \& Berry, 2008). Cronbach's Alpha scores for the six subscales with a sample of African American undergraduates ranged from .78 to .90 (Vandiver et al., 2002; Vandiver et al., 2001). Cronbach Alpha scores in a study of school-aged adolescents ranged from .65 to .88 (Gardner et al., 2007). Cronbach Alpha scores computed for the current sample are displayed in Table 3. 
Table 3

Internal Consistency Estimates (Cronbach's Alpha)

\section{Variable}

Vocational Outcome Expectations

Vocational Self Efficacy

Perception of Barriers

Pre Encounter Assimilation

Pre Encounter Miseducation

Pre Encounter Self-Hatred

Immersion Emersion Anti White

Internalization Afrocentric

Internalization Multicultural Inclusive

\section{$\boldsymbol{\alpha}$}

.96

.93

.81

.63

.75

.82

.85

.64

.75

\section{Hypotheses}

Based upon the developmental character of Nigrescence theory (Cross and Vandiver, 2001), the following relationships were expected:

Hypothesis 1: As youth age, they will increasingly endorse internalization attitudes (IA, IMCI) as measured by the CRIS.

Hypothesis 2: Internalization attitudes as measured by the CRIS will be positively related to career self efficacy.

Hypothesis 3: Internalization attitudes as measured by the CRIS will be positively related to career outcome expectations.

Hypothesis 4: Career self efficacy as measured by the VSSE will be negatively related to the perception of career barriers, as measured by the POBS. 
Hypothesis 5: Career outcome expectations as measured by the VOE will be negatively related to the perception of career barriers, as measured by the POBS.

Hypothesis 6: The perception of career barriers as measured by the POBS will increase as youth age.

Hypothesis 7: Age will be positively related to career self efficacy as measured by the VSSE.

Hypothesis 8: Age will be positively related to career outcome expectations as measured by the VOE.

Hypothesis 9: Internalization attitudes will be the most influential variables on career self efficacy (as measured by the VSSE), outweighing age, the perception of barriers (as measured by the POBS), or the other racial identity attitudes (as measured by the CRIS). Hypothesis 10: Internalization attitudes will be the most influential variables on career outcome expectations (as measured by the VOE), outweighing age, the perception of barriers (as measured by the POBS), or the other racial identity attitudes measured by the CRIS.

\section{Design}

Hypotheses 1 through 8 were analyzed using zero order correlation. A stepwise regression was used to explore the relationship between the independent variables age, identity attitudes (6), the perception of barriers, and the dependent variable career self efficacy. A second stepwise regression was used to explore the relationship between this same group of independent variables and the dependent variable career outcome expectations.

Independent variables: 
Career Related Racial Barriers - A participant's beliefs about the likelihood of facing racial discrimination in pursuit of a specific career.

\section{Identity Attitudes:}

Pre-encounter Assimilation (PA)

Pre-encounter Miseducation (PM)

Pre-encounter Self-Hatred (PSH)

Immersion-Emersion Anti-White (IEAW):

Internalization Afrocentricity (IA)

Internalization Multiculturalist Inclusive (IMCI)

Age - Calculated by date of birth

Dependent Variables:

Career-Related Self Efficacy - A participant's beliefs about his ability to succeed in a given career field based upon his perceptions of his own skills and abilities.

Career-Related Outcome Expectations - A participant's beliefs about the likelihood of a successful career outcome through sustained effort.

\section{Data Analysis}

The data was analyzed using Predictive Analytics Software (PASW) 17. Stevens (2002) suggests a minimum of 15 subjects per independent variable for a reliable regression equation in the social sciences. Accordingly, no more than eight predictors were employed in each regression analysis. With eight predictors, a sample size of 124 allowed the squared population multiple correlation to be set at .50 and provided a 
reasonable expectation that the loss in predictive power was less than .05 . For each regression equation, normality, homoscedasticity and linearity were assessed using a plot of the standardized residuals. Outliers were explored using a centered leverage value of $3 \mathrm{p} / \mathrm{n}$ as the threshold. Influential data points were to be examined using Cook's distance (Stevens, 2002). The adjusted $\mathrm{R}^{2}$ value was used to summarize how much variance in the dependent variable was accounted for by the model. Semipartial correlation and Beta coefficients were examined to determine the relative importance of each predictor in the equation. 


\section{CHAPTER IV}

\section{RESULTS}

The purpose of the study was to determine if racial identity attitudes, the perception of career related barriers, and age were significantly related to the Social Cognitive Career Theory variables of vocational self efficacy and vocational outcome expectations in African American adolescent males. Vocational self-efficacy was measured using the Vocational Skills Self Efficacy Scale (McWhirter, Rasheed, \& Crothers, 2000). Vocational outcome expectations were measured using the Vocational Outcome Expectancy Scale - Revised (McWhirter \& Metheny, 2009). Six racial identity attitudes were operationalized using the Cross Racial Identity Scale (Worrell, Vandiver, $\&$ Cross, 2004). The perception of career barriers was measured using the Perception of Barriers Scale (McWhirter, 1997).

Descriptive data will be presented, followed by correlations between the independent and dependent variables (Hypotheses 1 through 8 ), and results of the multiple regressions (Hypotheses $9 \& 10$ ).

\section{Descriptive Analyses}

Means and standard deviations for each scale and each subscale are displayed in Table 4 . 


\section{Table 4}

Range, Means and Standard Deviations of Independent and Dependent Variables

Independent Variables

Age

Perception of Barriers

Pre Encounter Assimilation

Pre Encounter Miseducation

Pre Encounter Self Hatred

Immersion-Emersion Anti-White

Internalization Afrocentric

Internalization Multicultural Inclusive
Observed Range

$12-19$

$1.0-5.0$

$1.0-7.0$

$1.0-7.0$

$1.0-7.0$

$1.0-7.0$

$1.0-7.0$

$1.0-7.0$

$0.0-9.0$
Mean

16.31

3.80

3.97

4.49

2.04

1.83

3.60

4.79

Dependent Variables

Vocational Self Efficacy

Vocational Outcome Expectations
$1.0-4.0 \quad 3.31$
1.37

$\underline{\mathrm{SD}}$

1.39

.58

1.29

1.30

1.31

1.09

1.08

1.05

Note. The Perception of Barriers scale is structured such that the lower the score, the higher the level of perceived barriers. The scale was reverse scored in order to maintain directional consistency with the other scales.

Observed responses encompassed the full range of each assessment instrument. In examining the means and standard deviations, it is important to note that the use of a selfselected, convenience sample in this study may have resulted in a restriction in the range of scores on the independent variables. As stated earlier, the distribution of ages was affected by the difficulty in obtaining parental permission from the freshman and middle school aged youth and is displayed in Table 5. 
Table 6

Correlations Between Independent Variables, Vocational Self Efficacy and Vocational Outcome Expectations

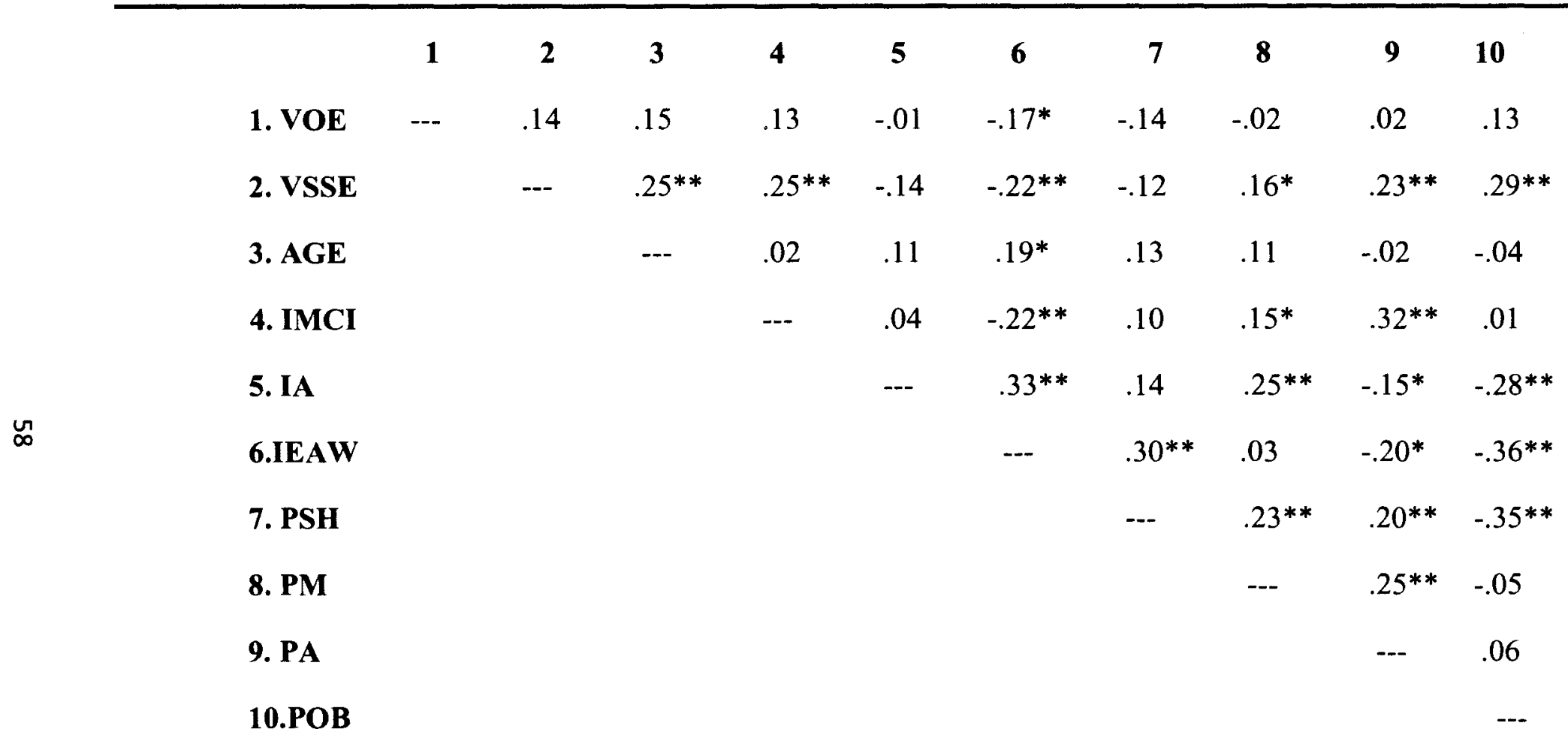

Note. $\mathrm{N}=124$ Abbreviations: VSSE - Vocational Self Efficacy; VOE - Vocational Outcome Expectations; POB - Perception of Barriers; PA - Pre Encounter Assimilation; PM - Pre Encounter Miseducation; PSH - Pre Encounter Self Hatred; IEAW - Immersion-Emersion Anti White; IA Internalization Afrocentric; IMCI - Internalization Multicultural Inclusive. $p<.05=*, p<.01=*$ 
The following hypotheses were examined using correlations between the independent and dependent variables as shown in Table 10.

Hypothesis 1: As youth age, they will increasingly endorse internalization attitudes. As a result, age will be positively related to $L A$, and age will be positively related to IMCI.

The correlations between age and IA $(r=.11)$, and IMCI $(r=.02)$ were not significant. This hypothesis was not supported.

Hypothesis 2: Internalization attitudes IA and IMCI will each be positively related to career self efficacy.

The correlation between IA and career self efficacy $(r=-.14)$ was negative and not significant. IMCI was positively related to career self efficacy $(r=.25, p<.01)$. This hypothesis was partially supported.

Hypothesis 3: Internalization attitudes IA and IMCI will each be positively related to career outcome expectations.

The correlations between career outcome expectations and IA $(r=-.01)$ and IMCI $(r=$ .13) were not significant. This hypothesis was not supported.

Hypothesis 4: Career self efficacy will be negatively related to the perception of career barriers.

Vocational self efficacy was found to be significantly related to the perception of career barriers $(r=.29, p<.01)$; however, the relationship was positive. The hypothesis was not supported.

Hypothesis 5: Career outcome expectations will be negatively related to the perception of career barriers. 
The correlation between career outcome expectations and the perception of career barriers $(r=.13)$ was not significant. The hypothesis was not supported.

Hypothesis 6: Age will be positively related to the perception of career barriers.

The correlation between age and the perception of career barriers $(r=-.04)$ was not significant. The hypothesis was not supported.

Hypothesis 7: Age will be positively related to career self efficacy.

Age was found to be positively related to career self efficacy $(r=.25, p<.01)$. The hypothesis was supported.

Hypothesis 8: Age will be positively related to career outcome expectations.

Age was not significantly related to career outcome expectations $(r=.15)$. The hypothesis was not supported.

\section{Multiple Regression Analyses}

Based upon the expected relationships articulated in the correlational hypotheses, two regression analyses were performed.

Hypothesis $9 a$ :

Age, the perception of career barriers, and the internalization attitudes IA and IMCI will be significantly related to career self efficacy. IMCI will be the most influential predictor of career self efficacy.

\section{Regression Analysis 1:}

A stepwise regression analysis was performed with career self efficacy as the dependent variable, and the following independent variables: the six racial identity 
attitudes, age and the perception of barriers. Plots of the data revealed no violations of normality, homoscedasticity, or linearity. Using the criteria of $\alpha=.05$ to enter and $\alpha=$ .10 to remove dependent variables, the final model retained three variables (perception of barriers, age, and internalized multicultural attitude). The final model was statistically significant, $F(3,120)=8.637, p<.05$, with an $\mathrm{R}$-square of .21 indicating that perception of barriers, age, and internalized multicultural attitude accounted for approximately $21 \%$ of the variance in vocational self efficacy in the sample. The adjusted R-square was .19, indicating that $19 \%$ of the variance in career related self efficacy in the population was explained by the variables of age, perception of barriers, and internalized multicultural attitude. A variance inflation factor of approximately 1.0 was observed for each predictor in the final model, indicating that there was no evidence of multicollinearity.

Unstandardized regression coefficients for the predictors were as follows: POB ( $\beta$ $=.531, p<.01)$, Age $(\beta=.194, p<.01)$, and IMCI $(\beta=.184, p<.01)$. Standardized beta coefficients were $\mathrm{POB}=.294, \mathrm{Age}=.257$, and $\mathrm{IMCI}=.239$. The standardized beta coefficients and the semi-partial correlation statistics for the given order of predictors $(\mathrm{POB}=.08, \mathrm{AGE}=.068, \mathrm{IMCI}=.057)$ indicate that the perception of barriers was the most influential variable in the model. However, the perception of career barriers was expected to have a negative relationship to career self-efficacy, but the opposite was found. The findings do not support the hypothesis. 
Hypothesis $9 b$ :

Age, the perception of career barriers, and the internalization attitudes IA and IMCI will be significantly related to career outcome expectations. IMCI will be the most influential predictor of career outcome expectations.

\section{Regression Analysis 2}

A stepwise regression analysis was performed with career outcome expectations as the dependent variable, and the following independent variables: the six racial identity attitudes, age and the perception of barriers. Using sequential stepwise regression with a criteria of $\alpha=.05$ to enter and $\alpha=.10$ to remove, no variables were retained in the final model.

Due to the lack of significance using stepwise regression, a simultaneous regression was performed with the same set of variables. The final model was not statistically significant, $F(8,115)=1.4, p=.20$, with an $\mathrm{R}$-square of .09 . The adjusted R-square was .03 , indicating that $3 \%$ of the variance in vocational outcome expectations was explained by the combined effects of the variables age, perception of barriers, and the racial identity attitudes Pre Encounter Assimilation, Pre Encounter Miseducation, Pre Encounter Self Hatred, Immersion-Emersion Anti White, Internalization Afrocentric and Internalization Multiculturalist Inclusive. Variance inflation factors ranged from 1.06 to 1.44 for the predictors in the final model, indicating that there was no evidence of multicollinearity. Standardized and unstandardized coefficients for the full model are reported in Table 7. 


\section{TABLE 7}

\section{Regression Coefficients}

\begin{tabular}{lcccc} 
Variable & B & $\boldsymbol{\beta}$ & Beta & Sig. \\
\hline Age & .10 & .05 & .19 & .045 \\
Perception of Barriers & .08 & .13 & .07 & .518 \\
Pre Encounter Assimilation & -.01 & .06 & -.01 & .982 \\
Pre Encounter Miseducation & -.02 & .06 & -.04 & .726 \\
Pre Encounter Self-Hatred & -.06 & .06 & -.10 & .313 \\
Immersion Emersion Anti White & -.10 & .07 & -.15 & .170 \\
Internalization Afrocentric & .04 & .07 & .06 & .564 \\
Internalization Multicultural Inclusive & .06 & .05 & .11 & .278 \\
\hline
\end{tabular}

Note. $\mathbf{B}=$ Unstandardized Coefficients; $\boldsymbol{\beta}=$ Standard Error; $\mathbf{B e t a}=$ Standardized Coefficients;

Sig. = Probability of $H o: \mathrm{B}=0$

Given the failure to generate a significant equation with all predictors entered simultaneously, a multiple regression was performed with IEAW and age, the two variables most highly related to VOE. A statistically significant model was produced, $F$ $(2,121)=4.02, p<.05$, with an R-square of .06 . The adjusted R-square was .05 , indicating that $5 \%$ of the variance in vocational outcome expectations was explained by the combined effects of age and the racial identity attitude Immersion-Emersion Anti White. Because the analysis required simultaneous entry, semi-partial correlations could not be determined. A variance inflation factor of 1.04 was observed for each predictor in the final model, indicating that there was no evidence of multicollinearity. Unstandardized regression coefficients for the predictors were as follows: IEAW ( $\beta=$ $.14, p<.05)$, and age $(\beta=.10, p<.05)$. Standardized beta coefficients were IEAW $=$ .21, and Age $=.19$, indicating no support for the hypothesis. 


\section{Summary}

A stepwise regression analysis was performed with career self efficacy as the dependent variable, and the following independent variables: the six racial identity attitudes (Pre Encounter Assimilation, Pre Encounter Miseducation, Pre Encounter Self Hatred, Immersion-Emersion Anti White, Internalization Afrocentric and Internalization Multiculturalist Inclusive), age, and the perception of barriers. The final model was statistically significant, $F(3,120)=8.637, p<.05$, with an R-square of .21 indicating that perception of barriers, age, and an internalized multicultural attitude account for approximately $21 \%$ of the variance in vocational self efficacy in the sample. The adjusted R-square was .19 , indicating that $19 \%$ of the variance in career related self efficacy in the population is explained by the variables of age, perception of barriers, and internalized multicultural attitude.

A second stepwise regression analysis was performed with career outcome expectations as the dependent variable, and the following independent variables: the six racial identity attitudes (Pre Encounter Assimilation, Pre Encounter Miseducation, Pre Encounter Self Hatred, Immersion-Emersion Anti White, Internalization Afrocentric and Internalization Multiculturalist Inclusive), age and the perception of barriers. Using sequential stepwise regression with a criteria of $\alpha=.05$ to enter and $\alpha=.10$ to remove, no variables were retained in the final model.

Given the failure to generate a significant equation for career outcome expectations with all predictors entered, a multiple regression was performed with IEAW and age, the two variables most highly related to VOE. A statistically significant model was produced, $F(2,121)=4.02, p<.05$, with an R-square of .06. The adjusted R-square 
was .05 , indicating that $5 \%$ of the variance in vocational outcome expectations was explained by the combined effects of age and the racial identity attitude ImmersionEmersion Anti White. 


\section{CHAPTER V}

\section{DISCUSSION}

The study first assessed the relationships among male African American adolescent's ages, their racial identity attitudes, their perceptions of career barriers and career self-efficacy. A second regression assessed the relationships among male African American adolescent's ages, racial identity attitudes, perceptions of career barriers and career outcome expectations. A summary of the study including findings, conclusions, study limitations, and implications for future research and practice will be presented in this chapter.

\section{Findings}

Career self-efficacy was regressed on eight variables, producing a final model including the perception of barriers, age, and an internalized multicultural attitude. The model accounted for $19 \%$ of the variance in career self-efficacy, with the perception of barriers representing the most influential variable in the equation. A second regression using career outcome expectations as the dependent variable and the same eight predictors showed that only the racial identity attitude Immersion-Emersion Anti-White was significantly related to career outcome expectations. No other predictors entered into the second regression resulted in a significant relationship. Definitions for the six racial identity attitudes measured by the CRIS are located in Chapter IV. 


\section{Conclusions}

From a developmental perspective, the finding that age, the perception of barriers and a multicultural inclusive attitude are positively associated with career self-efficacy was expected. However, no interaction among age, the perception of barriers and a multicultural inclusive attitude was observed. An unexpected aspect of the findings was that the perception of barriers was the most influential predictor of self-efficacy, and that a higher level of perceived barriers was associated with higher career self-efficacy. Two previous studies using the VSSE found the opposite relationship, that a high perception of barriers was associated with lower self-efficacy (Ali et al., 2005; McWhirter et al., 2000). However, Rollins and Valdez (2006) encountered results similar to the current study from a sample that included male and female African American $11^{\text {th }}$ and $12^{\text {th }}$ graders. Finding that students who perceived a higher degree of racism reported higher career decision making efficacy, the researchers concluded that African American students may develop effective coping mechanisms through other socialization effects such as a supportive home environments or community cohesiveness. The authors also argued that in order for students to cope with racism, there must first be an awareness among the students that racism exists. Lent et al. (2000) cautioned that the perception of barriers can become conflated with coping efficacy, particularly if the barriers are located in the future, along a temporal continuum. For youth in the current sample, it appears that those who hold a high degree of efficacy for career success anticipate career barriers and perceive them as a necessary task to overcome. Unfortunately, the size of the current sample and the 
limitations associated with adequate power precluded the addition of a coping efficacy measure, tempering the ability to further interpret this finding.

The variable age had much less influence than was hypothesized. Although previous use of the CRIS with adolescents found Multicultural Inclusive attitudes to be more common in high school students than middle school students (Gardner-Kitt \& Worrell, 2007), age in the current sample was significantly related only to the ImmersionEmersion Anti-White attitude. It should be noted that in both the current and GardnerKitt and Worrell (2007) studies, internalization attitudes (Afrocentric, Multicultural Inclusive) occur more frequently than is suggested by the developmental aspects of Nigrescence theory (Cross 1971, 1991; Cross \& Vandiver, 2001), It is also noteworthy that the pattern of mean scores for the six subscales of the CRIS in the current sample is very similar to those in Worrell's 2008 study Figure 1.

\section{Figure 1}

\section{Mean Subscale Scores, Worrell 2008 Sample}

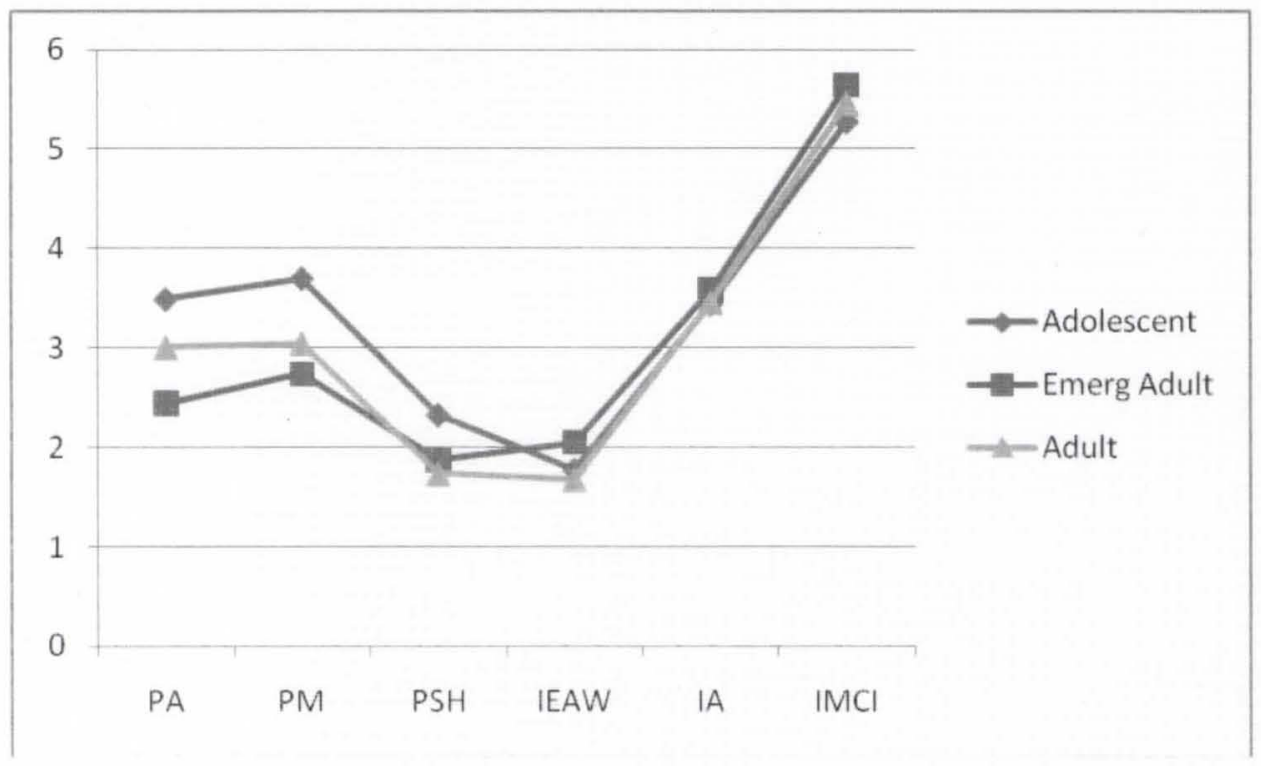


This finding is difficult to adequately interpret given the multidimensional nature of a given CRIS profile and the lack of longitudinal data. However, the similarity of the racial attitude profiles in the two studies is surprising, given that researchers have suggested that the racial identity profiles of the CRIS will be largely determined by socialization experiences such as parental influence, or other social factors that would be expected to vary across contexts (Cross \& Vandiver, 2001; Gardner-Kitt \& Worrell, 2007; Worrell, 2008). From a theoretical perspective, the similarities in the CRIS profiles between the adolescents in this sample and the adolescents, young adults, and mature adults in the Worrell (2008) sample suggest some degree of similar socialization experiences. Possible similarities include the fact that the youth in the current sample were all attending school and all volunteered for the project with parental support, suggesting some level of interest in career development on the part of both the students and parents. The 143 adolescents in the Worrell (2008) study were also a convenience sample, as were the students in the current study. Students in the current sample came from public or charter schools in middle/working class communities. The same is reported about the adolescent's communities in the Worrell (2008) sample. The emerging adult sample consisted of 309 African American students at a Northeastern University, reportedly from middle and working class communities. Over half (55.2\%) of the adult sample were current graduate students, with $84 \%$ of the graduate students reporting income, indicating that these were largely individuals currently engaged in the workforce. Sixty-seven percent of the non-students in the adult sample reported having obtained a professional, graduate or bachelor's degree. The pattern of means between the 
two studies most closely resembles the Multiculturalist racial identity profile identified by Worrell et al. (2006).

\section{Figure 2}

Cluster Analysis of Racial Identity Profiles (Worrel et al. 2006)

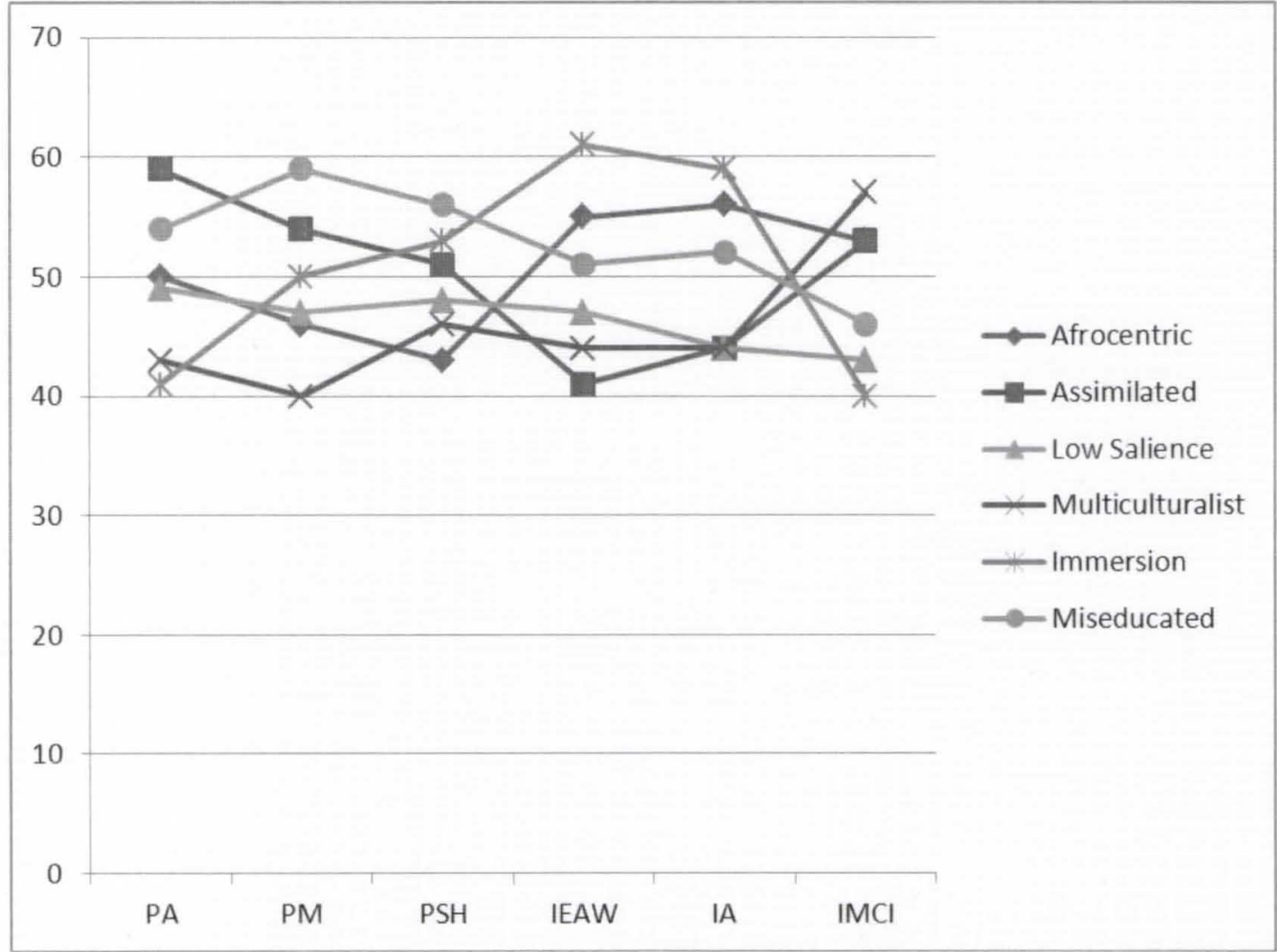

The findings suggest that the socialization influencing racial identity profiles in the current study may be related in some context to the Multiculturalist profile in the Worrell et al. 2006 study. Further research is needed.

It was expected that age, the perception of career related barriers, and internalization attitudes would also be significantly related to outcome expectations. This hypothesis was not supported. In fact, outcome expectations were not found to be significantly related to career self-efficacy, one of the basic premises of SCCT. Using 
Lent and Brown's (2006) discussion on assessing social cognitive constructs, it may be that for the African American adolescent males in the current sample a higher level of specificity may have been needed for assessing the outcome expectation domain. For example, in a study of math-based career outcome expectations and African American middle school adolescents, math-based outcome expectations were found to be positively related to parental support and negatively related to institutional racism (Alliman-Brisset \& Turner, 2009).

Anti-White attitudes were, in fact, the only significant predictor of outcome expectations in the current sample. The relationship was such that higher levels of AntiWhite attitudes predicted lower outcome expectations. In previous studies of African American adolescents, outcome expectations were also found to be negatively related to racism (Alliman-Brissett \& Turner, 2010), negative peers (Cunningham, Corprew, \& Becker, 2009), and cultural mistrust (Irving \& Hudley, 2005). The findings in the current study were consistent with these and suggest that some level of negative coping, as described by Noguera (2008) and Spencer et al. (2001), was present in the sample and had a negative impact on career outcome expectations. This does not, however, explain the lack of a significant relationship that SCCT would predict between outcome expectations and self-efficacy. Irving and Hudley (2005) suggest that due to cultural mistrust, African American adolescents consciously lower outcome expectations as a protective mechanism to preserve perceptions of self-worth. Rather than risk failure, the authors hypothesized that students lower the value of the particular domain (academics, career) and seek alternative domains for success (social, athletic activities). This process suggests a conscious effort to "de-link" outcome expectations from self-efficacy, and 
may offer some explanation for the current findings. Further research in this area is needed.

The developmental components of Nigrescence theory holds that Anti-White attitudes will be most prevalent among adolescents, as youth are theorized to be most vulnerable to an emotional reaction to racism (Cross, 1971, 1991; Cross \& Vandiver, 2001). The findings on the low levels of Anti-White attitudes across the sample are not consistent with this premise. Anti-White attitudes represented the lowest mean subscale scores in the study. It should also be noted that the next least endorsed subscale among the boys in the current study was the Pre-encounter Self Hatred attitude. A recent study of African American college students indicated that the Pre-encounter Self Hatred (anger turned inward) and Immersion Emersion Anti-White (anger turned outward) were the only racial identity attitudes found to be significantly related to psychological distress (Worrell, Mendoza-Denton, Telesford, Simmons, \& Martin, 2011). The findings in the present sample do not show high levels of either attitude

\section{Study Limitations}

It is probable that the use of a self-selected, convenience sample introduced some degree of bias into the observed results. Selection bias was a particular concern given that youth who participated in the study were required to take consent forms home for parental signature. Those who returned the form may have held a greater degree of interest in the subject matter than the non-respondents, a greater degree of bonding to the school, or simply a more supportive home environment. As such, generalization of the sample results to the population may be problematic. It also proved to be extremely difficult to obtain parental consent forms from the freshman and middle school youth. 
This resulted in a limited number of youth who participated in the study that were under the age of 15. As a result, the sample is heavily weighted with older adolescents at the high school level. Again, the restricted range makes it difficult to generalize the findings. However, it should be noted again that the results of the CRIS from the current sample were substantially consistent with previous use of the CRIS with African American adolescents (Worrell, 2008).

With respect to the CRIS, the internal consistency estimates for the subscales Pre Encounter Assimilation and Internalization Afrocentric were below .70 $(\mathrm{PA}=.63 ; \mathrm{IA}=$ .64). Previous use of the CRIS with adolescents also resulted in a Pre Encounter Assimilation subscale estimate below .70 (Gardner-Kitt \& Worrell, 2007), confirming that the lower reliability of the subscale is not unique to this sample. The CRIS was designed for the specific purpose of improving the internal reliability of the RIAS-B and has shown consistent Cronbach Alpha reliability coefficients above .70 with adults (Worrell, 2008). However, this does not appear to hold with adolescents. Research findings on African American adolescents utilizing the CRIS have been published in three separate articles (Worrell \& Gardner-Kitt, 2006; Gardner-Kitt \& Worrell, 2007; Worrell, 2008); however, each article used the data originating from the same sample, suggesting that further psychometric research on the CRIS with adolescents is needed.

Specific academic data on the participants was not collected, thus the findings do not answer the question of whether the level of career self-efficacy reported by the students in the sample is based upon past academic performance, vicarious learning, or a realistic appraisal of the skills and preparation necessary for career success. However, according to the Ohio Department of Education's 2009-2010 Academic Report Cards 
from each of the schools represented by students in the sample, the percentage of African American students scoring at the basic or limited proficiency level in each district was at least twice the rate of White students. In each district, the percentage of Whites scoring accelerated or advanced outnumbered Blacks in every academic category. Future studies of self-efficacy among African American adolescents may benefit from the inclusion of variables that reflect current academic status, such as grade point average or disciplinary records.

\section{Implications for Future Research}

The similarities of the racial identity profiles between the current sample and the Worrell (2008) group imply that the two groups share an educational value. Future studies may be able to gather more empirical evidence for relationships between specific racial identity profiles and other values associated with work and career development. Results of the current study also suggest that for future research with African American adolescents exploring career barriers, the use of a coping efficacy assessment tool may provide greater illumination of a subject's perception of barriers, reducing the likelihood that this variable becomes conflated with coping efficacy. Finally, future research longitudinal designs on racial identity attitudes in adolescence should pay particular attention to the social and contextual factors that influence the identity development process. Studies of within group differences could include examples such as gender, SES, and students in good school standing as compared to students who have dropped out, been suspended or expelled, incarcerated, or court-involved. 


\section{Implications for Counseling Practice}

Given the results of the Perception of Barriers measure it is evident that the students in the study have an expectation of future challenges to career success. Using the framework articulated by Noguera (2008), structural and cultural barriers can combine to depress African American achievement. It may be beneficial for counselors to help students explore whether they perceive these challenges as structural or cultural in nature, and then help students begin to develop specific strategies to overcome the barriers. In addition, the high level of efficacy reported by the students was not negatively affected by the perception of barriers, nor was the efficacy related to positive outcome expectations. This may suggest that counselors should help African American students explore the reasons for their confidence in a successful career, as studies have shown that African American students, in particular, have positive abstract expectations for school and education, but relatively low achievement (Trusty, 2000).

\section{Concluding Summary}

The findings of the study indicate that for adolescent African American males, older age, a multicultural inclusive racial identity attitude, and an increased perception of career barriers are associated with a higher degree of career self efficacy. No interaction among the independent variables was observed. The findings do not support a developmental continuum for racial identity theory as proposed by Nigrescence (Cross, 1971, 1991; Cross \& Vandiver, 2001; Cross \& Fhagen-Smith, 2001). This finding is consistent with more recent research on racial identity attitudes as measured by the CRIS (Worrell et al, 2006; Worrell \& Gardner-Kitt, 2006; Gardner-Kitt \& Worrell, 2007; Worrell, 2008). The findings suggest that it is possible for African American males to 
have a well-developed, internalized racial identity by adolescence, and that perceived barriers may not negatively influence career self efficacy. However, future work on the psychometric reliability of the CRIS with adolescents may be warranted. 


\title{
REFERENCES
}

\begin{abstract}
Ainsworth-Darnell, J. W., \& Downey, D. B. (1998). Assessing the oppositional culture explanation for racial/ethnic differences in school performance. American Sociological Review, 63 (4), 536-553.
\end{abstract}

\begin{abstract}
Albert, K. A., \& Luzzo, D. A. (1999). The role of perceived barriers in career development: A social cognitive perspective. Journal of Counseling and Development, 77 (4), $431-436$.
\end{abstract}
Ali, S. R., McWhirter, E. H., \& Chronister, K. M. (2005). Self efficacy and vocational outcome expectations for adolescents of lower socioeconomic status: A pilot study. Journal of Career Assessment, 13 (1), 40 - 58.

Ali, S. R., \& Saunders, J. L. (2006). College expectations of rural appalachian youth: An exploration of social cognitive career theory factors. Career Development Quarterly, 55 (1), 38-51 
Alliman-Brissett, A., \& Turner, S., (2010). Racism, parent support, and math-based career interests, efficacy, and outcome expectations among African American adolescents. Journal of Black Psychology, 36 (2), $197-225$.

Arbuthnot, K. (2009). The effects of stereotype threat on standardized mathematics test performance and cognitive processing. Harvard Educational Review, 79 (3), $448-472$.

Aronson, J., Lustina, M. J., Good, C., Keough, K., Steele, C. M., \& Brown, J. (1999). When White men can't do math: Necessary and sufficient factors in stereotype threat. Journal of Experimental Social Psychology, 35 (1), 29-46.

Bandura, A. (1977). Social learning theory. Englewood Cliffs, New Jersey: PrenticeHall.

Bandura, A. (1982). Self-efficacy mechanism in human agency. American Psychologist $37(2), 122-147$.

Bandura, A., Barbaranelli, C., Vittorio, C., \& Pastorelli, C. (2001). Self-efficacy beliefs as shapers of children's aspirations and career trajectories. Child Development, 72 (1), 187-206. 
Battin-Pearson, S., Newcomb, M. D., Abbott, R. D., Hill, K. G., Catalano, R. F., \& Hawkins, J. D. (2000). Predictors of early high school dropout: A test of five theories. Journal of Educational Psychology, 92 (3), 568 - 582.

Battu, H., Mwale, M., \& Zenou, Y. (2007). Oppositional identities and the labor market. Journal of Population Economics, 20 (3), 643-667.

Bell, D. (1973). Race, racism and american law. New York: Little, Brown \& Company Bergin, D. A., \& Cooks, H. C. (2002). High school students of color talk about accusations of acting white. Urban Review, 34 (2), 113.

Betz, N. E. (1994). Self-concept theory in career development and counseling. The Career Development Quarterly, 43 (1), 32.

Betz, N., \& Hackett, G. (2006). Career self-efficacy theory: Back to the future. Journal of Career Assessment, 14 (3), 3 - 11.

Betz, N., \& Taylor, K. M. (1994). Manual for the career decision-making self-efficacy scale. Columbus, OH: Department of Psychology, The Ohio State University. 
Blustein, D. (2006). The psychology of working. Mahwah: Lawrence Erlbaum Associates.

Brown, D. (2002). Career choice and development. San Francisco: Jossey-Bass.

Buck, S. (2010). Acting White: The ironic legacy of desegregation. New Haven \& London: Yale University Press.

Byars-Winston, A. M. (2006). Racial ideology in predicting social cognitive career variables for Black undergraduates. Journal of Vocational Behavior, 69, 134-148.

Caldwell, C. H., Kohn-Wood, L. P., Schmeelk-Cone, K. H., Chavous, T. M., \& Zimmerman, M.

A. (2004). Racial discrimination and racial identity as risk or protective factors for violent behaviors in African American young adults. American Journal of Community Psychology, $33(1 / 2), 91-107$.

Carter, R. T. (1995). The influence of race and racial identity in psychotherapy: Toward a racially inclusive model. New York: John Wiley and Sons

Chavous, T. M., Bernat, D. H., Schmeelk-Cone, K., Caldwell, C. H., Kohn-Wood, L., \& Zimmerman, M. A. (2003). Racial identity and academic attainment among African American adolescents. Child Development, 74 (4), 1076-1090. 
Clark, K. B., \& Clark, M. K. (1939). Segregation as a factor in the racial identification of Negro pre-school children: A preliminary report. Journal of Experimental Education, 8 (2), $161-163$.

Clark, K. B., \& Clark, M. K. (1940). Skin color as a factor in racial identification of Negro preschool children. Journal of Social Psychology, 11, 159 - 169.

Clark, K. B., \& Clark, M. K. (1950). Emotional factors in racial identification and preference in Negro children. Journal of Negro Education, 19 (3), 341 - 350.

Cokley, K. (2002). Testing cross's revised racial identity model: An examination of the relationship between racial identity and internalized racism. Journal of Counseling Psychology, 49 (4), 476-483.

Cokley, K. (2005). Racialized identity, ethnic identity, and afrocentric values: Conceptual and methodological challenges in understanding African American identity. Journal of Counseling Psychology, 52 (4), 517 - 526.

Cokley, K. (2007). Critical issues in the measurement of ethnic and racial identity: A referendum on the state of the field. Journal of Counseling Psychology, 54 (3), 224-234. 
Cokley, K., McClain, S., Jones, \& M., Johnson, S. (2011). A preliminary investigation of academic disidentification, racial identity, and academic achievement among African American adolescents. The High School Journal, 95 (2), 54 - 68.

Constantine, M. G. (2002). The intersection of race, ethnicity, gender, and social class in counseling: Examining selves in cultural contexts. Journal of Multicultural Counseling and Development, 30, 210 - 215.

Constantine, M., Wallace, C., \& Kindaichi, M. (2005). Examining contextual factors in the career decision status of African American adolescents. Journal of Career Assessment, 13 (3), 307 - 319.

Cook, P. J., Ludwig, J. (1997). Weighing the burden of acting White: are there race differences in attitudes toward education? Journal of Policy Analysis and Management, $16(2), 256-278$.

Cross, W. E. (1971). The Negro to Black conversion experience. Black World, 20, 13 27.

Cross, W. E. (1991). Shades of Black. Philadelphia: Temple University Press. 
Cross, W. E., \& Fhagen-Smith, P. (2001). Patterns of African American identity development: A lifespan perspective. In Wijeyesinghe, C. L., Jackson, B. W. (Eds.), New perspectives on racial identity development: $A$ theoretical and practical anthology. New York: New York University Press.

Cross, W. E., \& Vandiver, B. J. (2001). Nigrescence theory and measurement: Introducing the Cross racial identity scale (CRIS). In Ponterotto, J., Casas, J., Suzuki, L., \& Alexander, C. (Eds.), Handbook of multicultural counseling. Thousand Oaks, CA: Sage.

Cunningham, M., Corprew, C., \& Becker, J. (2009). Associations of future expectations, negative friends, and academic achievement in high-achieving African American adolescents. Urban Education, 44 (3), 280 - 296.

Day-Vines, N., \& Day-Hairston, B. (2005). Culturally congruent strategies for addressing the behavioral needs of urban, African American male adolescents. Professional School Counseling, 8(3), 236 - 243.

DeCuir-Gunby, J. T. (2007). Negotiating identity in a bubble: A critical race analysis of African American high school students' experiences in an elite, independent school. Equity \& Excellence in Education, 40 (1), 26-35. 
Delgado, R., \& Stefancic, J. (2001). Critical race theory: An introduction. New York: New York University Press.

Downey, D. \& Ainsworth-Darnell, J. (2002) The search for oppositional culture among Black students. American Sociological Review, 67 (1), 156-164.

Duncan, G. A. (2002). Beyond love: A critical race ethnography of the schooling of adolescent Black males. Equity \& Excellence in Education, 35 (2), 131-143.

Duncan, G. A. (2005). Critical race ethnography in education: Narrative, inequality and the problem of epistemology. Race, Ethnicity \& Education, 8(1), 93-114.

Erikson, E. H. (1959). Identity and the life cycle. Reprinted 1980, New York/London: W.W. Norton \& Company.

Evans, A., Copping, K., Rowley, S., \& Kurtz-Costes, B., (2011). Academic self-concept in Black adolescents: Do race and gender stereotypes matter? Self and Identity, 10, 263277.

Fordham, S., \& Ogbu, J. (1986). Black student's school success: Coping with the burden of acting White. Urban Review, 18, 176 - 206.

Fouad, N. A., \& Smith, P. L. (1996). A test of a social cognitive model for middle school students: Math and science. Journal of Counseling Psychology, 43, 338-346. 
Fryer, R. G. (2006). Acting White. Education Next, 6, (1). Retrieved March 8, 2011 from: http://educationnext.org/actingwhite/

Gainor, K. A., \& Lent, R. W. (1998). Social cognitive expectations and racial identity attitudes in predicting the math choice intentions of Black college students. Journal of Counseling Psychology, 45 (4), 403-413.

Gardner-Kitt, D. L., \& Worrell, F. C. (2007). Measuring nigrescence attitudes in schoolaged adolescents. Journal of Adolescence, 30 (2), 187-202.

Gregory, A., \& Thompson, A., (2010). African American high school students and variability in behavior across classrooms. Journal of Community Psychology, 38, (3), 386-402.

Harris, A. L. (2006). I (don't) hate school: Revisiting oppositional culture theory of Blacks' resistance to schooling. Social Forces, 85 (2), 797-834.

Harris, A. L. (2008). Optimism in the face of despair: Black-White differences in beliefs about school as a means for upward social mobility. Social Science Quarterly, 89, (3), $608-630$.

Helms, J. E. (2007). Some better practices for measuring racial and ethnic identity constructs. Journal of Counseling Psychology, 54 (3), 235-246. 
Helms, J. \& Parham, T. (1990). Black racial identity attitudes scale (form RIAS-B). In Helms, J. (Ed.) Black and White racial identity. New York: Greenwood.

Horowitz, E.L., \& Horowitz, R. E. (1938). Development of social attitudes in children. Sociometry, $1(3 / 4), 301-338$

Horowitz, R. (1939). Racial aspects of self-identification in nursery school children. The Journal of Psychology, (7), $91-99$.

Irving, M. A., \& Hudley, C. (2005). Cultural mistrust, academic outcome expectations, and outcome values among African American adolescent men. Urban Education, 40, 476 $-496$.

Kerpelman, J. L., \& Mosher, L. S. (2004). Rural African American adolescents' future orientation: The importance of self-efficacy, control and responsibility, and identity development. Identity, 4 (2), 187-208.

Ladson-Billings, G., \& Tate, W. F., (1995). Toward a critical race theory of education. Teachers College Record, 97(1), 47-67. 
Lent, R. W., \& Brown, S. D. (2006). On conceptualizing and assessing social cognitive constructs in career research: A measurement guide. Journal of Career Assessment, 14 (1), 12-35.

Lent, R. W., Brown, S. D., \& Hackett, G. (1994). Toward a unifying social cognitive theory of career and academic interest, choice, and performance. Journal of Vocational Behavior, $45,78-122$.

Lent, R. W., Brown, S. D., \& Hackett, G. (2000). Contextual supports and barriers to career choice: A social cognitive analysis. Journal of Counseling Psychology, 47 (1), 36 49.

Lent, R. W., G. Hackett, \& Brown, S. D. (1999). A social cognitive view of school-towork transition. Career development quarterly, 47 (4), 297-311.

Lent, R. W., Larkin K. C., \& Brown, S. D. (1986). Self-efficacy in the prediction of academic performance and perceived career options. Journal of Counseling Psychology, 33 (3), 265 - 269. 
Levine, M. (2012). Race and male employment in the wake of the great recession: Black male employment rates in Milwaukee and the nation's largest metro areas. Center for Economic Development, Working Paper January, 2012. Retrieved May 31, 2012 from: http://www4.uwm.edu/ced/publications/black-employment_2012.pdf

Livingston, J. N., \& Nahimana, C. (2006). Problem child or problem context: An ecological approach to young black males. Reclaiming children and youth, 14 (4), 209 214.

Luzzo, D. A., \& McWhirter, E. H. (2001). Sex and ethnic differences in the perception of educational and career-related barriers and levels of coping efficacy. Journal of Counseling \& Development, 79 (1), 61 - 67.

Majors, R., \& Billson, J. (1993). Cool pose: The dilemma of Black manhood in America. New York: Simon \& Schuster.

Marcia, J. E. (1967). Ego identity status: Relationship to change in self-esteem, 'general maladjustment,' and authoritarianism. Journal of Personality, 35 (1), 118.

McKown, C., \& Weinstein, R. S. (2003). The development and consequences of stereotype consciousness in middle childhood. Child Development, 74 (2), 498-515. 
McMahon, S. D., \& Watts, \& R. J. (2002). Ethnic identity in urban African American youth: Exploring links with self-worth, aggression, and other psychosocial variables. Journal of Community Psychology, 30 (4), 411-431.

McWhirter, E. H. (1997). Perceived barriers to education and career: Ethnic and gender differences. Journal of Vocational Behavior, 50 (1), 124-140.

McWhirter, E. H., \& Metheny, J., 2009. Family of origin influences on the career development of young adults: The relative contributions of social status and parent support on social-cognitive variables. Manuscript in progress.

McWhirter, E. H., Rasheed, S., \& Crothers, M. (2000). The effects of high school career education on social cognitive variables. Journal of Counseling Psychology, 47 (3), 330 341.

Metheny, J., McWhirter, E. H., \& O’Neil, M. E. (2008). Measuring perceived teacher support and its influence on adolescent career development. Journal of Career Assessment, 16 (2), $218-237$.

Miller, D. B. (1999). Racial socialization and racial identity: Can they promote resiliency for African American adolescents? Adolescence, 34 (135), 493 - 501. 
Miller, D. B., \& MacIntosh, R. (1999). Promoting resilience in urban African American adolescents: Racial socialization and identity as protective factors. Social Work Research, $23(3), 159-170$.

Multon, K. D., Brown, S. D., \& Lent R. W. (1991). Relation of self-efficacy beliefs to academic outcomes: A meta-analytic investigation. Journal of Counseling Psychology, $38(1), 30-38$.

National Center for Education Statistics, (1994). NAEP 1994 reading report card for the nation and states. Retrieved November 28, 2012 from:

http://nces.ed.gov/nationsreportcard/pdf/main1994/96045.pdf

Noguera, P. (2001). The role and influence of environmental and cultural factors on the academic performance of African American males. In motion magazine, Retrieved February 20, 2009 from http://www.inmotionmagazine.com/pnaamale1.html

Noguera, P. (2008). The trouble with Black boys... and other reflections on race, equity and the future of public education. San Francisco, CA: Jossey-Bass.

Noguera, P. A., \& Wing, J. Y. (Eds.). (2006). Unfinished business: Closing the achievement gap in our schools. San Francisco: Jossey Bass. 
Ogbu, J. U. (2003). Black American students in an affluent suburb: A study of academic disengagement. Mahwah, New Jersey: Lawrence Erlbaum Associates.

Ogbu, J. U. (2004). Collective identity and the burden of "acting White" in Black history, community and education. The Urban Review, $36(1), 1-35$.

Ogbu, J. U. (2008). Minority status, oppositional culture and schooling. New York: Routledge.

Oyserman, D., Gant, L., \& Ager, J. (1995). "A socially contextualized model of African American identity: Possible selves and school persistence. Journal of Personality \& Social Psychology, 69 (6), 1216-1232.

Paa, H., \& McWhirter, E. (2000). Perceived influences on high school students' current career expectations. The Career Development Quarterly, 49, 29 - 49.

Parham, T. A. (1989). Cycles of psychological nigrescence. The Counseling Psychologist, 17 (2), 187-226.

Parham T. A., Helms, J. E. (1981). The influence of Black students' racial identity attitudes on preferences for counselor's race. Journal of Counseling Psychology, 28 (3), $250-257$. 
Parham, T. A., \& Helms, J. E. (1985). Relation of racial identity attitudes to selfactualization and affective states of Black students. Journal of Counseling Psychology, $32(3), 431-440$.

Peterson-Lewis, S., \& Bratton, L. M. (2004). Perceptions of "acting Black" among African American teens: Implications of racial dramaturgy for academic and social achievement. Urban Review, 36 (2), 81-100.

Phinney, J. S. (1989). Stages of ethnic identity development in minority group adolescents. The Journal of Early Adolescence, 9 (1-2), 34-49.

Phinney, J., \& Ong, A. (2007). Conceptualization and measurement of ethnic identity: Current status and future directions. Journal of Counseling Psychology, 54 (3), 271-281.

Quimby, J., Wolfson, J., \& Seyala, N. (2007). Social cognitive predictors of African American

adolescents' career interests. Journal of Career Development, 33 (4), 376 - 394.

Quintana, S. (2007). Racial and ethnic identity: Developmental perspectives and research. Journal of Counseling Psychology, 54 (3), $259-270$.

Rice, F. P. (2001). Human Development (4ed.), Upper Saddle River, N.J.: Prentice Hall 
Rollins, V. B., \& Valdez, J. N. (2006). Perceived racism and career self-efficacy in African American adolescents. Journal of Black Psychology, 32 (2), 176 -198.

Sanders Thompson, V. L. (1992). A multifaceted approach to the conceptualization of African American identification. Journal of Black Studies, 23 (1), 75 - 85.

Sanders Thompson, V. L. (1995). Sociocultural influences on African-American racial identification. Journal of Applied Social Psychology, 25 (16), 1411-1429.

Sanders Thompson, V. L. (2001). The complexity of African American racial identification. Journal of Black Studies, 32 (2), 155 - 165.

Sanders, V. L. \& M. Akbar (2003). The understanding of race and the construction of African American identity. Western Journal of Black Studies, 27 (2), 80-88.

Scott Jr., L. D. (2003). The relation of racial identity and racial socialization to coping with discrimination among African American adolescents. Journal of Black Studies, 33 (4), 520 .

Scott Jr., L. D. (2004) Correlates of coping with perceived discriminatory experiences among African American adolescents. Journal of Adolescence, 27, 123-137. 
Seaton, E. K., Sellers, R. M., \& Scottham, K. M. (2006). The status model of racial identity development in African American adolescents: Evidence of structure, trajectories, and well-being. Child Development, 77 (5), 1416-1426.

Sellers, R. M., Copeland-Lindner, N., Martin, P. P., \& Lewis, R. L. (2006). Racial identity matters: The relationship between racial discrimination and psychological functioning in African American adolescents. Journal of Research on Adolescence, 16 (2), $187-216$.

Sellers, R. M., Shelton, N., Cooke, D., Chavous, T., Rowley, S. J., \& Smith, M. (1998). A multidimensional model of racial identity: Assumptions, findings and future directions. In R. L. Jones (Ed.), African American identity development: Advances in African American psychology (p. 275 - 302). Hampton, VA: Cobb \& Henry.

Simmons, C., Worrell, F. C., \& Berry, J. M. (2008). Psychometric properties of scores on three Black racial identity scales. Assessment, 15 (3), 259-276.

Smith, S. (2004). Career barriers among information technology undergraduate majors. Information Technology, Learning, and Performance Journal, 22 (1), 49 - 56. 
Spencer, M.B., (2011). American identity: Impact of youths' differential experiences in society on their attachment to American ideals. Applied Developmental Science, 15 (2), 61-69.

Spencer, M. B., Dupree, D., \& Hartmann, T. (1997). A phenomenological variant of ecological systems theory (PVEST): A self-organization perspective in context. Development and Psychopathology, 9 (4), 817-833.

Spencer, M. B., Fegley, S., \& Harpalani, V. (2003). A theoretical and empirical examination of identity as coping: Linking coping resources to the self processes of African American youth. Applied Developmental Science, 7 (3), 181-188.

Spencer, M. B., \& Harpalani, V. (2008). What does "acting White" actually mean: Racial identity, adolescent development, and academic achievement among African American youth. In J. Ogbu (Ed.) Minority status, oppositional culture and schooling, (222 - 239). New York: Routledge.

Spencer, M. B., \& Markstrom-Adams, C. (1990). Identity processes among racial and ethnic minority children in America. Child Development, 61 (2), 290 - 310.

Spencer, M. B., Noll, E., Stoltzfus, J., \& Harpalani, V. (2001). Identity and school adjustment: Revisiting the "acting White" assumption. Educational Psychologist, 36 (1), 21-30. 
Steele, C. M. (1997). A threat in the air: How stereotypes shape intellectual identity and performance. American Psychologist, 52 (6), 613-629.

Steele, C. M. (1999). Thin ice. Atlantic Monthly, 284 (2), 44-54.

Steele, C. M., \& Aronson, J. (1995). Stereotype threat and the intellectual test performance of African Americans. Journal of Personality \& Social Psychology, 69 (5), 797-811.

Stevens, J. P. (2002). Applied multivariate statistics for the social sciences (4ed.). Lawrence Erlbaum Associates: Mahwah, New Jersey.

Swanson, D., Spencer, M., Dell'Angelo, T., Harpalani, V., \& Spencer, T., (2002). Identity processes and the positive youth development of African Americans: An explanatory framework. New Directions For Youth Development, 95, 73-99

Sum, A., \& Khatiwada, I., (2010). Labor underutilization problems of U.S. workers across household income groups at the end of the great recession: A truly great depression among the nation's low income workers amidst full employment among the most affluent. Center for Labor Market Studies Publications, Paper 26. Retrieved May 31, 2012 from: http://hdl.handle.net/2047/d20000593 
Tate, W. F. (1997). Critical race theory and education: History, theory, and implications. Review of Research in Education, 22, 195-247.

Taylor, R. L. (1995). African American youth: Their social and economic status in the United States. Westport, Connecticut: Praeger

Thomas, D. E., Townsend, T. G., \& Belgrave, F. (2003). The influence of cultural and racial identification on the psychosocial adjustment of inner-city African American children in school. American Journal of Community Psychology, 32 (3/4), 217-228.

Trusty, J. (2000) High educational expectations and low achievement: stability of educational goals across adolescence. The Journal of Educational Research 93, 356-365. United States Department of Labor. (2011). The Black labor force in the recovery. Federal Publications. Paper 843. Retrieved May 31, 2012 from:

$\underline{\text { http://digitalcommons.ilr.cornell.edu/key workplace/843 }}$

United States Bureau of Labor Statistics. $(2007,2012)$. Labor force statistics from the current population survey. Retrieved May 31, 2012 from:

http://data.bls.gov/cgi-bin/surveymost.

Vandiver, B., Cross, W., Worrell, F., \& Fhagen-Smith, P. (2002). Validating the Cross racial identity scale. Journal of Counseling Psychology, 49 (1), 71-85. 
Vandiver, B. J., Fhagen-Smith, P. E., Cokley, K. O., Cross, W. E., Jr, \& Worrell, F. C. (2001). Cross's nigrescence model: From theory to scale to theory. Journal of Multicultural Counseling \& Development, 29 (3), 174.

Walsh, W. B., Bingham, R. P., Brown, M. T., \& Ward, C. M. (Eds.) (2001). Career counseling for African Americans. Mahwah, N.J.: Lawrence Erlbaum Associates

Weller, C.,\& Fields, J., (2011). The Black and White labor gap in America: Why African Americans struggle to find jobs and remain employed compared to Whites. Center for American Progress. Retrieved May 31, 2012 from:

http://www.americanprogress.org/issues/labor/report/2011/07/25/9992/the-black-andwhite-labor-gap-in-america/

Williams, B. T. (2004). The truth in the tale: Race and "counterstorytelling" in the classroom. Journal of Adolescent and Adult Literacy, 48 (2), 164-169.

Wilson, W. J. (2009). More than just race. New York: Norton.

Worrell, F. C. (2008). Nigrescence attitudes in adolescence, emerging adulthood, and adulthood. Journal of Black Psychology, 34 (2), 156-178. 
Worrell, F. C., Cross, W. K., Jr, \& Vandiver, B. J. (2001). Nigrescence theory: Current status and challenges for the future. Journal of Multicultural Counseling \& Development, $29(3), 201$.

Worrell, F., \& Gardner-Kitt, D. L. (2006). The relationship between racial and ethnic identity in Black adolescents: The Cross racial identity scale and the multigroup ethnic identity measure. Identity, 6 (4), $293-315$.

Worrell, F., Mendoza-Denton, R., Telesford, J., Simmons, C., \& Martin, J. (2011). Cross racial identity scale (CRIS) scores: Stability and relationships with psychological adjustment. Journal of Personality Assessment, 93 (6), 637 - 648.

Worrell, F., Vandiver, B., \& Cross, W., (2004). The Cross racial identity scale, $2^{\text {nd }}$ ed. Unpublished manuscript.

Worrell, F. C. \& Watson, S. (2008). A confirmatory factor analysis of Cross racial identity scale (CRIS) scores: Testing the expanded nigresence model. Education and Psychological Measurement, 68 (6), $1041-1058$.

Yanico, B. J., Swanson, J. L., \& Tokar, D. M. (1994). A psychometric investigation of the Black racial identity attitude scale-form b. Journal of Vocational Behavior, 44 (2), $218-234$. 
Yasui, M., Dorham, C. L., \& Dishion, T. J. (2004). Ethnic identity and psychological adjustment: A validity analysis for European American and African American adolescents. Journal of Adolescent Research, 19 (6), 807-825.

Youngblood, J., Spencer, M. B., (2002). Integrating normative identity processes and academic support requirements for special needs adolescents: The application of an identity-focused cultural ecological (ICE) perspective. Applied Developmental Science, 6 (2), 95-108. 


\section{CURRICULUM VITAE}

NAME:

ADDRESS:

DOB:

\section{EDUCATION}

\& TRAINING:
Norman L. Townsel Jr.

6088 Beckett Station Ct., West Chester, Ohio 45069

Hamilton, Ohio - August 16, 1960

B.S., Business Administration

University of Maryland

$1982-1987$

M.Ed., Counseling and Human Development

Lindsey Wilson College

$2000-2003$

Ph.D., Counseling \& Personnel Services, Counselor Education - Mental Health Counseling $2005-2012$

LICENSES: $\quad$ Licensed Professional Clinical Counselor Commonwealth of Kentucky

$2005-2012$

Licensed Professional Clinical Counselor, Supervisor State of Ohio $2005-2012$ 